\title{
Hybrid Organic-Inorganic Scaffolding Biomaterials for Regenerative Therapies
}

\author{
Nadège Sachot ${ }^{1,2}$, Elisabeth Engel ${ }^{3,1,2}$ and Oscar Castaño $0^{1,3,2,4^{*}}$
}

${ }^{1}$ Biomaterials for Regenerative Therapies, Institute for Bioengineering of Catalonia (IBEC), Barcelona, Spain; ${ }^{2}$ CIBER Bioingenieria, Biomateriales y Nanomedicina (CIBER-BBN), Zaragoza, Spain; ${ }^{3}$ Department of Materials Science and Metallurgical Engineering, Universitat Politècnica de Catalunya (UPC), Barcelona, Spain; ${ }^{4}$ Materials Science and Metallurgical Engineering, Universitat de Barcelona (UB), Barcelona, Spain

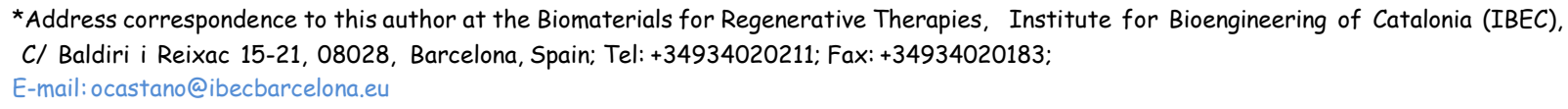

Article Details: Current Organic Chemistry, Vol. 18, Issue 18, 2299-2314 (2014) http://dx.doi.org/10.2174/1385272819666140806200355

\begin{abstract}
The introduction of hybrid materials in regenerative medicine has solved some problems related to the mechanical and bioactive properties of biomaterials. Calcium phosphates and their derivatives have provided the basis for inorganic components, thanks to their good bioactivity, especially in bone regeneration. When mixed with biodegradable polymers, the result is a synergic association that mimics the composition of many tissues of the human body and, additionally, exhibits suitable mechanical properties. Together with the development of nanotechnology and new synthesis methods, hybrids offer a promising option for the development of a third or fourth generation of smart biomaterials and scaffolds to guide the regeneration of natural tissues, with an optimum efficiency/cost ratio. Their potential bioactivity, as well as other valuable features of hybrids, open promising new pathways for their use in bone regeneration and other tissue repair therapies. This review provides a comprehensive overview of the different hybrid organic-inorganic scaffolding bio- materials developed so far for regenerative therapies, especially in bone. It also looks at the potential for research into hybrid materials for other, softer tissues, which is still at an initial stage, but with very promising results.
\end{abstract}

Keywords: Biodegradable polymer, hybrid materials, nanoparticles, ormoglass.

\section{INTRODUCTION}

Many strategies involving composites have been implemented since the 80s, particularly for second generation biomaterials $[1,2]$. The development of hybrid materials (i.e. composites whose components demonstrate interactions at the molecular or nanometric level) in regenerative medicine accomplishes several requirements that pure materials cannot fulfill, especially those linked to mechanical issues. The possibility of introducing the inherent bioactivity of calcium phosphates $(\mathrm{CaP})$ is a bonus that makes any composite involving $\mathrm{CaP}$ very interesting.

The main aim of composite materials in therapies is to obtain templates which have suitable mechanical properties, as well as bioactivity. Nowadays, their potential use can be extended to almost all human tissues. However, the main field whose requirements have triggered the development of composite and hybrid materials has been bone regeneration, as a way to develop a third and fourth generation of smart biomaterials and scaffolds to guide the regeneration of natural tissue $[1,3]$. The use of hybrids in other branches of regeneration is an easy step forward thanks to their potential bioactivity and versatile features. In this review, we will describe recent developments using hybrid inorganic/organic materials which have already been developed for tissue regeneration. In addition, we discuss carbon nanotubes (CNT) and their derivatives, as they have gained popularity in several applications in the field of tissue regeneration, in particular nerve and muscle regeneration. Even though carbon nanotubes are not inorganic materials, they present some similar properties to inorganic materials, and we con- sider that they also deserve our attention.

In today's biomaterials for tissue regeneration, the trend is to be able to mimic the natural extracellular matrix (ECM) with its corresponding features, functions and hierarchical organization [3]. Bone, for example, is the result of an osteoblast-mediated mineralized ECM or osteoid, whose Young modulus goes from $27 \mathrm{kPa}$ to $1 \mathrm{GPa}$, referred to as final rigid bone [4]. These values have generated a controversy in bone regeneration: should implanted grafts be as rigid as bone, or should high stiffness be relinquished for the final result? In addition, mature bone is made up of different components, each with a specific role within a comprehensive function. Function strongly depends on architecture, which 
is why there is no universal bone substitute, but instead specific designs for particular applications.

\section{INTRODUCTION TO BONE TISSUE}

Basically, bone tissue is a strong and tough connective tissue that supports and protects the rest of the internal organs, allows the body to move, offers an ideal environment for blood cell formation, and acts as a store for salts (especially calcium phosphates), among other functions [5]. Bone, as a hybrid natural construct, is an inspiring material that presents a complex and highly hierarchical organized structure [6]. Morphologically, it can be subdivided into two distinct types according to porosity and unit microstructure: the cortical bone (also known as compact bone) and the trabecular bone (also called cancellous or spongy bone) $[7,8]$. The cortical bone is distinguished by its high density (low porosity and void spaces) and represents the higher percentage of the total bone mass of an individual (around $80 \%$ ). It typically forms the outer shell of most bones and supports the mechanical properties of the skeleton. The trabecular bone is defined by its low density and accounts for the other $20 \%$ of the total bone mass of an adult. It possesses a significantly higher surface area, and its high porosity allows room for blood vessels and bone marrow.

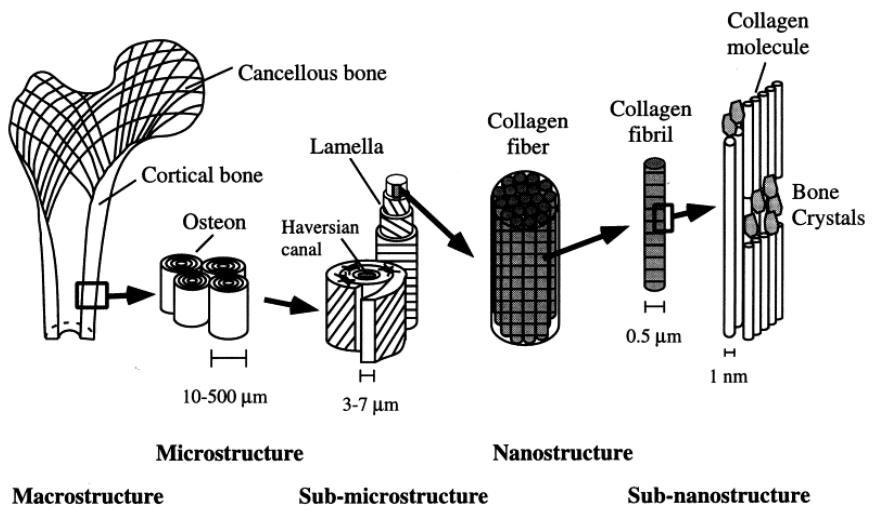

Fig. (1). Hierarchical structural organization of bone. (scheme reprinted from [7] with permission).

Cortical and trabecular bones are both made of nearly the same organic and inorganic components (Fig. 1). The combination of these two phases with different natures makes bone a composite tissue. Each component phase contributes to the unique mechanical properties of bone and depends on the structural organization of each phase [7]. Generally, it is commonly accepted that the organic part provides elasticity and flexibility to the bone, whereas the inorganic one provides rigidity and load-bearing strength [6]. The major organic constituents are collagens organized in fibril bundles that form a 3D nanoscaled collageneous matrix network [7,9]. Proteoglycans, noncollageneous macromolecules (other proteins like osteocalcin, osteopontin, bone morphogenetic protein-2 (BMP-2), etc) [6] and cells complete the organic composition. The inorganic constituent is mainly formed by carbonated hydroxyapatite, a calcium phosphate mineral with low crystallinity and some amounts of carbonate that epitaxially nucleates and grows along the collagen fibrils.

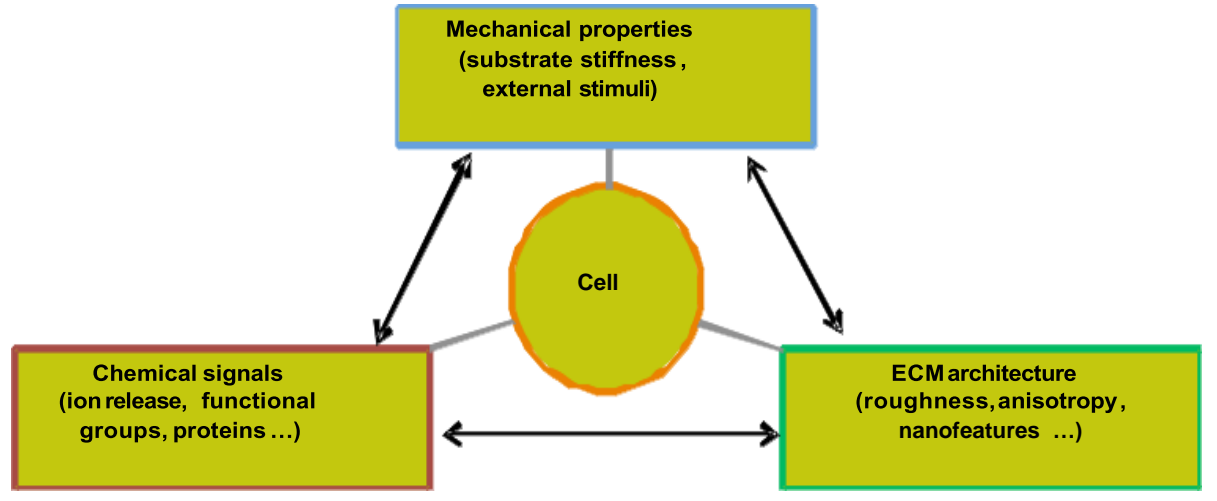

Fig. (2). Dynamic dependence between the various features of 3D scaffolds on cells and involved in the regulation of a material's biological performance. (scheme adapted from [13]).

\section{SCAFFOLD PROPERTIES AND THEIR EFFECT ON CELLULAR BEHAVIOR}

Adhesion, proliferation and differentiation of cells cultured on a scaffold constitute the basis of tissue engineering approaches. It is well known that cell-cell interactions direct cellular activity towards these behaviors and contribute to determining the fate of uncommitted stem cells $[10,11]$. In addition, the material properties also directly affect cell function; in fact, these can be efficiently used to control cellular processes through three-dimensional chemical and physical 
guidance. The key design factors in developing a biomaterial aimed at triggering specific cellular responses are its chemical and mechanical surface properties and its architecture (Fig. 2). Together, all these material properties coordinate the interplay be- tween intrinsic and extrinsic determinants of stem cell fate to pro- duce a desired phenotype [12, 13].

\subsection{Scaffold Architecture}

The choice of a suitable fabrication technique to produce 3D structures is a significant hurdle for the improvement of tissue engineering treatments [14]. The architecture of the fabricated material should, in fact, not only have suitable mechanical properties, but also enable an optimal mass and fluid transport through the whole template [15]. In other words, the substrate prepared should exhibit a suitable porosity to ensure the efficient colonization of the material by cells, enable the supply of nutrients and oxygen, ensure the evacuation of detritus, and support the invasion of blood vessels. All these phenomena will contribute to the performance of the material and, ultimately, to the formation of fully functional and healthy bone. Appropriate porosity is thus a crucial requirement for bone regeneration [16].

As seen in (Fig. 3), materials can be shaped into different forms depending on the processing techniques used to fabricate scaffolds (foaming [17, 18], sintering [19], salt leaching [20], rapid- prototyping [21], electrospinning [22], etc). Each technique results in materials with specific pore size and interconnectivity, which can be controlled by varying the experimental parameters [23]. Porosity can be considered at three levels: macro-, meso- and microporosity. Macroporosity refers to pores having a width larger than $50 \mathrm{~nm}$, mesoporosity to those between 2 and $50 \mathrm{~nm}$, and microporosity to those with a width smaller than $2 \mathrm{~nm}$ [24].

Macroporosity is considered the most relevant factor that influences cell behavior, bone growth and vascularization. For example, Valerio et al. demonstrated that bioactive glass macroporous structures with pores ranging from $100 \mu \mathrm{m}$ to 500 $\mu m$ (prepared by the sol-gel method and foaming technique) support cell migration to- wards the inside of the scaffold [25]. Sepulveda et al. and Xynos et al. also showed that foams with large pores (diameters between 10 and $500 \mu \mathrm{m}$ ) enhanced cellular differentiation and proliferation, as well as bone formation and vascularization [26, 27]. According to Hulbert et al., the minimum size requirement for macropores is around $100 \mu \mathrm{m}$ [28]. In their study in dogs, they showed that samples with pores between $75 \mu \mathrm{m}$ to $100 \mu \mathrm{m}$ induced only little bone ingrowth, whereas samples with pores ranging from $100 \mu \mathrm{m}$ to $150 \mu \mathrm{m}$ in size promoted better bone ingrowth and the formation of calcified tissue. Samples with pores smaller than 75 um were infiltrated by fibrous connective tissue only.
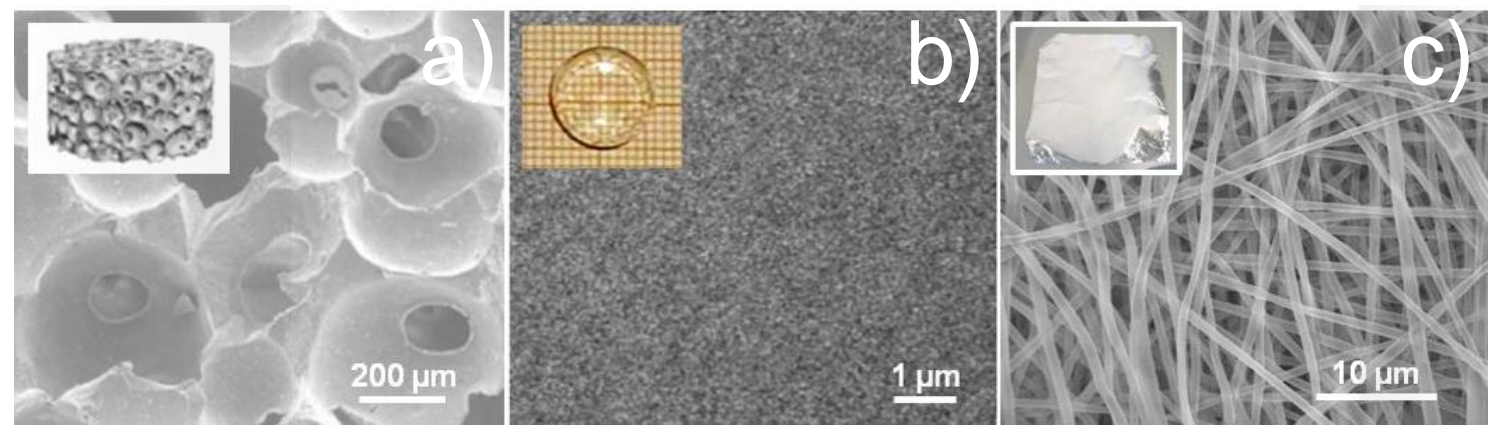

Fig. (3). Examples of hybrid scaffolds prepared using different process techniques (from left to right): foams, monoliths, fibers. (picture $a$ is adapted from [17] and from [18] with permissions, picture b from [19] with permission, picture $c$ from the author's own propriety).

The samples with the largest pores in the study (150-200 $\mu \mathrm{m})$ exhibited the best results in terms of calcification, vascularization and the presence of unmineralized bone within the pores. They justified the relevance of their results by correlating their observations with the diameter of the normal harversian system (100-200 $\mu \mathrm{m})$. This showed the critical importance of macroporosity on cellular response in terms of osteo- and angiogenesis. However, depending on the testing conditions (load bearing or non-load bearing conditions), the critical pore size mentioned by Hulbert and coworkers appears not to be universal $[29,30]$. Also, results differ between in vitro and in vivo assays, which make it difficult to define precise criteria for the size of macropores. In in vitro conditions, a low porosity can stimulate osteogenesis by suppressing cell proliferation and forcing cell aggregation, while in in vivo conditions, a higher porosity and pore size promoted better bone ingrowth due to good vascularization and oxygenation, thus favoring osteogenesis [15]. Moreover, the optimal or range of optimal pore size required for bone regeneration has been suggested to be dependent on each distinct cell type, and has also been shown to possess an upper limit of efficient functionality [31]. Finally, the interconnectivity of pores is essential for bone regeneration as it enables the infiltration of bone, the development of an efficient network 
of blood vessels, and the promotion of cell- cell interactions $[16,25,32]$.

On the other hand, meso- and microporosity also affect cellular response. The presence of these very small pores increases the surface area of the scaffold, promotes the adsorption of biological metabolites such as proteins, and enhances cell adhesion [33,34]. The roughness created by these small pores can favor the anchorage of cells, and improves the proliferation and differentiation of bone cell lineage [34-36]. In parallel, in the case of biodegradable materials, it contributes to better ion exchange and bone-like apatite formation by the dissolution and re-precipitation process [37]. Simon et al. showed that geometrical parameters (pore size and the spatial arrangement of pores) affect the pattern of bone ingrowth [38]. The ability to vary and control the level of the three different types of porosity (i.e. meso-, microand macroporosity) is, therefore, a key factor in the development of scaffolds for bone tissue engineering. As previously explained, the sol-gel technology ap- pears to be a noteworthy method of tailoring cellular response by varying porosity, because it enables the control of the macroporosity of materials by using different fabrication methods to tune their texture at the meso- and micro levels [27, 39]. It should be noticed, however, that the porosity of the material always has to be a com- promise between biological behavior and mechanical properties, as a too high void volume may provide good vascularization and osteointegration, but significantly decreases the scaffold's resistance to mechanical failure [40].

Another predominant research topic regarding the optimization of bone tissue repair is the ability to control cell-ECM interactions and to optimize cellular responses by producing materials with features tailored at the micro- and nanoscales. If roughness can be achieved through the fabrication of meso-microporous scaffolds, it can also be tailored by engineering the surface of materials using various techniques. The texturing and patterning of a material's surface [41] can be performed using blasting [42], electropolishing [43], chemical treatments [44], lithography [45],plasma treatment [46] and focused ion beam [47], among other methods. It is well known that micro- and nanofeatures (roughness, for example) created on the surface positively affect cellular response (adhesion, detachment, proliferation, differentiation, spreading) compared to materials prepared with a smooth topography [43, 48]. Materials with nanofeatures are even thought to be more suitable than ones with microfeatures because they may be more biomimetic, and are consequently better at guiding cell behavior [49].

The base membranes of various tissues are composed of complex mixtures of nanoscale pits, pores, striations, particles, fibers and protrusions [48]. Based on a study conducted by Palin et al., the replication of nanoscale bone roughness on material surfaces indeed induces greater bone-forming cell adhesion and proliferation [50]. Other researchers have also shown that, for some materials, the smaller the nanofeatures, the better the cell adhesion and differentiation [5154]. However, it is difficult to establish a limit range of nanotopographic scale, in which bone regeneration is positively affected due to the diversity in topographic characteristics associ- ated to the different studies mentioned above (size, uniformity and shape). What is clear is that nanotopography controls cell behavior through the regulation of focal adhesion formation and cytoskeleton contractility, and activation of processes taking place at the sub-cell level (gene upregulation, cell signaling, cell metabolism) $[45,49,54]$.

However, the physical surface patterning or texturing approach is not only used to modify the nanotopography of a material in terms of depth, pattern size or shape. It also enables the control of the anisotropy of a material's surface, a property to which cells are highly sensitive too. Cells cultured on grooved substrates, for ex-ample, elongate and align in the direction of the groove [55,56] (Fig. 4a).
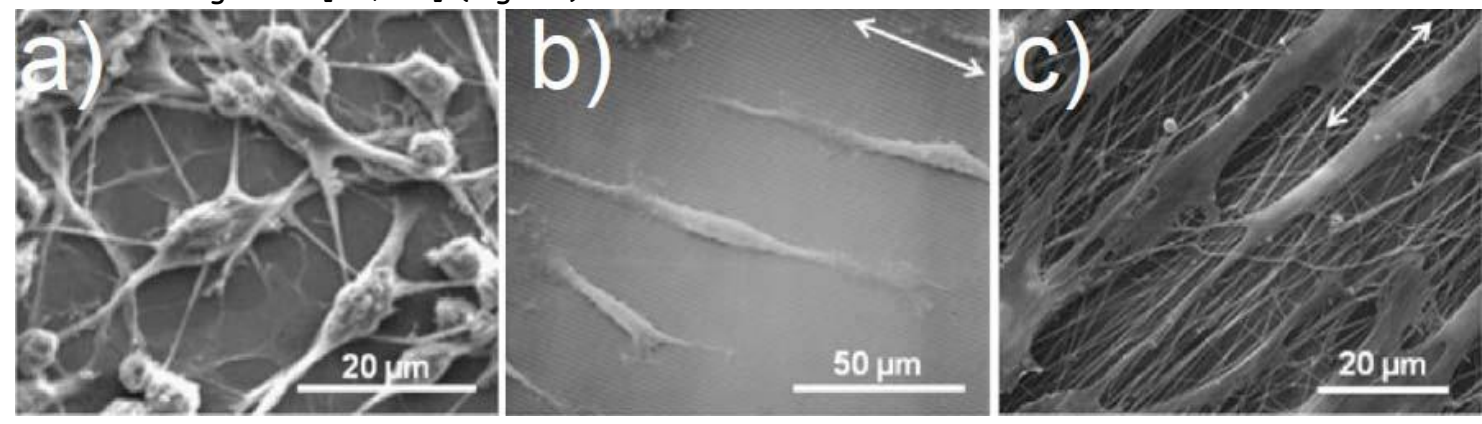

Fig. (4). Examples of morphology of cells cultured on a) tissue culture plate, e.g, not patterned or textured surface b) grooved substrate and c) aligned electrospun fibers. Arrows symbolize the direction of the anisotropy. (picture a is adapted from [57], picture b from [55] and picture $c$ from [59] with permissions).

The degree of alignment seems to be directly related to the depth of the grooves [56, 57], which demonstrates once again the importance of the roughness and the interplay of various physical factors for cellular activity. The spatial arrangement of fibers produced by electrospinning also induced similar responses [57, 58]. When cultured on aligned fibrous mats, cells oriented them- selves in the direction of the anisotropy (Fig. 4b) [55]. In contrast, on non-woven mats, cells spread following the multi-directions of the random fiber organization. In addition to this physical guidance, electrospun 
fibers present numerous particular advantages for bone tissue engineering (Fig. 4c) [59].

In summary, material properties directly influence bone formation in tissue engineering. Both physical and chemical cues play a role in the targeting of specific cellular responses required for the regeneration of a fully healthy functional bone (osteo- and angiogenesis). The choice of material constituents, the nature of the functional groups present at the material surface, the stiffness, rough- ness, nanofeatures and topography, among others, are many of the parameters that influence the mechanism. It is, however, difficult to investigate the role of each factor in an independent manner, as all of them are related. What is clear, though, is that bone formation is the result of a dynamic dependence between numerous properties, and that alongside cell-cell interactions and external mechanical stimulus, cell-biomaterial interactions account for an essential part of the regeneration process. Given the diversity of the materials currently produced, it is necessary to specify that each material possesses a unique combination of properties, and that each tem- plate will require specific improvements in order to achieve the proper biological performance. This should be achievable by finding a good compromise between all the criteria that the ideal scaf-fold should fulfill (mechanical properties, biological response, sterilizability, etc). Up to now, no ideal material has been developed - even though some are promising - and the design of biomaterials remains a challenging field of research with many and various development perspectives.

\subsection{Scaffold Surface Chemical Properties}

Scaffold surface chemical properties depend on the compounds selected to prepare the material (composition), the processing method, and an eventual functionalization step that can be per- formed on the surface after fabrication. Each biomaterial therefore possesses specific surface properties, such as for example wettability, electric charge, protein adsorption ability and bioactivity, which regulate the biological performance of the scaffold. One of the factors that can be considered to explain these differences in properties and in cellular response induced by the material is the nature of the functional groups present on its surface [60]. Hence, Lee et al. demonstrated that the functionalization of polyethylene substrates with different organic functional groups $\left(\mathrm{COOH}, \mathrm{CH}_{2} \mathrm{OH}, \mathrm{CONH}, \mathrm{CH}_{2} \mathrm{NH}_{2}\right)$ resulted in a better cellular adhesion [61]. This was explained by a better wettability of the functional groups on grafted surfaces in comparison to non-grafted ones. They also showed that the chemistry of the functional groups itself was important, as it modifies the electric charge of the polymeric surface. Negatively charged substrates showed poor cell adhesion, whereas the positive ones exhibited the best. On neutral surfaces (- $\mathrm{CH}_{2} \mathrm{OH}$ and $\mathrm{CONH}_{2}$ groups), cell adhered better on hydroxyl-grafted substrates, possibly because of specific hydrogen bonding created between the surface hydroxyl groups of the polymer and the polar groups of the cell surfaces $[62,63]$. However, the adhesion was still lower than on positively charged materials. Cell replication followed the same tendency as the cell adhesion assay: the more hydrophilic the material, the better the proliferation. Finally, it was demonstrated that substrates inducing the best proliferation were not necessarily those with the best cellular spreading. Indeed, cells spread significantly on the neutral surfaces, despite proliferating less than on the positively charged surfaces. The authors suggested that the compatibility between the cells and the surface chemistry plays a direct role in cellular spreading. Other research groups also described the general observations made by Lee et al. and gave further evidence that the nature of functional groups can also trigger osteoblastic differentiation [64, 65].

Other studies reported in the literature shows, moreover, that cell behavior can be influenced by these functional groups in an indirect manner: the surface properties that functional groups pro- vide to the material affect protein adsorption and, consequently, the cellular response [66-68]. Arima et. al. examined the kinetics of protein adsorption on materials having different functional groups and identified a correlation with cell adhesion [69]. Results showed that, depending on the chemistry of the functional groups exposed at the materials' surfaces, non cell-adhesive proteins such as bovine serum albumin (BSA) previously adsorbed on self-assembled monolayers of alkanethiols (SAMs) were more or less rapidly replaced by cell-adhesive proteins (fibronectin, vitronectin, etc). This induced difference in cell adhesion: SAMs terminated with $\mathrm{COOH}$ groups supported a better cell adhesion than ones having $\mathrm{NH}_{2}$ groups. This was explained by the slower protein displacement process in $\mathrm{NH}_{2}$-terminated materials. Thus, the efficiency of protein displacement (rate and amount of replaced proteins) ultimately modulated cell adhesion, as it is well known that cell-adhesive proteins, natural or engineered, adsorbed or covalently linked to materials, facilitate cell adhesion [66, 70]. Currently, the grafting of biomolecules (peptides or proteins) is in fact an approach extensively used in tissue engineering to guide cellular adhesion and activity [71, 72]. In this case, ligand identity, conformation and density are key parameters when developing materials [12, 73] because they regulate the efficiency of integrin-mediated cell adhesion [74], modulate the matrix deposition by osteogenic cells [75] and control the cell-type specificity of these responses [76].

The last factor related to the surface that should be considered when developing smart artificial materials is the ions dissolution that occurs alongside the material resorption [77]. Nowadays, bio- active glasses are one of the materials most able to stimulate osteogenesis and angiogenesis due to their ion release ability [78-82]. The dissolution products of bioactive glasses (calcium, silicon, titanium, phosphate or another element used as a doping constituent) modify the chemical 
physiological environment of biological entities, and consequently mediate the cell metabolism. Extracellular $\mathrm{Ca}^{2+}$, for example, is known for interacting with bone cells by

affecting their calcium-sensing receptors (CaSR) and directly activating intracellular mechanisms [83]. Concretely, one study per- formed by Honda et al. demonstrated that extracellular calcium increases the expression of the insulin-like growth factor 2 (IGF-II), which mediates the subsequent increase in human osteoblast proliferation. Other studies revealed that cell migration, proliferation and

differentiation may be controlled by the activation of various CaSR- mediated intracellular signaling pathways $[84,85] . \mathrm{Ca}^{2+}$ is therefore very important for bone remodeling and can be used in scaffolds for

bone tissue engineering to serve as an extracellular messenger that guides the cell behavior of osteoblastic cell lineage. In fact, it is already commonly accepted that ions released from silicon-based bioactive glasses play a critical role in that direction. Xynos et al. in 2001 were the first to suggest that ion products of bioactive glass dissolution have a direct effect on the gene expression profile of human osteoblasts; more precisely, on genes relevant to osteoblast metabolism and bone homeostasis [86]. More recently, an osteogenic glass based on a titanium network has also been shown to act as a gene expression regulator able to stimulate the activation of genes involved in angiogenesis [87]. The up-regulation of gene expression that can be achieved by the use of bioactive glasses in tissue engineering is thus a very promising approach to control cellular activity towards the desired responses. However, it should be stressed that the concentrations of these ions is critical, and that the precise control of the material dissolution rate should be required in order not to induce cytotoxicity [88].

The ion concentration and release kinetics of bioactive glasses can be controlled by the material composition [89] or by the fabrication polymer/bioactive glasses constructs [90]. However, in some cases it is still extremely difficult to precisely monitor the features of the ion release of the inorganic phase in a predetermined manner, as it is often embedded in the organic matrix. This affects the dissolution of the bioactive glass and consequently its ability to trigger the desired cellular response (cell adhesion, spreading, proliferation, differentiation and migration) [87, 91]. This problem also affects the mineralization potential of the materials $[92,93]$. For these reasons, the tailoring of the chemical material surface properties is essential.

\subsection{Mechanical Properties of Scaffolds}

In addition to the influence that chemical surface properties of a material have on cellular activity, there is significant evidence that the other physical properties of the substrates also contribute to stem cell fate determination [94]. One of them is the material's mechanical properties, e.g. its stiffness or elasticity. The local mechanical interactions between cells and their microenvironment regulate cell shape, organization and differentiation of the different tissues $[95,96]$ as can be observed in (Fig. 5) [97-107]. This observation is true in the natural environment as well as in artificial 3D structures. Cells are able to discriminate between different ranges of stiffness in their microenvironment, and to respond to this stimulus by pulling on the extracellular matrix. The contractile forces that cells exert on the matrix result in tensile stresses in the cytoskeleton. This phenomenon occurs through the transmission of force between the cell and the cellular cytoskeleton by means of focal adhesions (cell-extracellular matrix contacts) [13]. The pathway of force transmission from inside the cell to the elastic matrix is pro- vided by actin structures that are in turn linked to focal adhesions $[108,109]$, and by well-known signaling proteins such as rho guanosine triphosphatase (Rho GTPase) associated with the focal adhesion complexes which act as mechanotransducers [110,111]. These intracellular forces regulate the signaling pathways involved in the fundamental processes that determine cell functions. A very popular study conducted with gels by Engler et al. demonstrated that the elastic modulus of the matrix plays a role in directing stem cell lineage specifications [4]. Contractile forces in the cytoskeleton are suggested to be driven by actin-myosin action and to regulate human stem cell differentiation. Soft substrates mimicking the stiff- ness of the brain tissue induced cell differentiation towards a neurogenic lineage, whereas cells cultured on substrates with intermediate and higher stiffness mimicking that of muscle and bone tis- sues respectively evolved towards myogenic and osteogenic cells. They also showed that cells adjust their internal stiffness to match that of the substrate. Stiffer matrices, in fact, produced stiffer and increasingly tense cells. Solon et al. made similar observations with fibroblasts using soft elastic substrates [99].

Although it is recognized that the stiffness of materials has an effect on cell behavior, it should be emphasized that the stiffness alone does not always seem to be an efficient cell differentiation parameter. For example, Rowlands et al. Showed that, unlike in Engler and coworkers' findings, the substrate stiffness alone was not sufficient to achieve osteogenic differentiation of mesenchymal stem cells (MSCs) in the stiffness range that they investigated [112]. The coating of the gel with biomolecules, such as collagen, fibronectin or laminin, was necessary to induce this phenotype. The type of molecules present on the material surface, in fact, modulates the differentiation process for a given substrate stiffness. Their study thus demonstrated that there is feedback between the material stiffness and the adhesive ligand 
as regards osteogenic differentiation. For myogenic differentiation this observation is also valid, but the interplay of these two extracellular environmental factors seems to be less obvious. This difference was attributed to a predisposition of MSCs to differentiate into myogenic lineage in comparison to osteogenic lineage when cultured on the studied substrates.

The studies mentioned here thus highlight the difficulties in clearly defining how each material parameter, in an individual manner, can be responsible for the triggering of a specific cell phenotype. Such assays often lead to controversial discussions because the conditions in which the material is investigated usually differ from one study to another (cell type used, cell badge, parameters set for the assay, material conditioning, etc). Nevertheless, it is commonly accepted that, whether combined with other factors or not, a material's mechanical properties play an important role in the de- termination of cell behavior. This is particularly clear when looking at the numerous studies reported in the literature on cells and mechanosensing, mechanotransduction and mechanoresponse $[95,111,113]$.

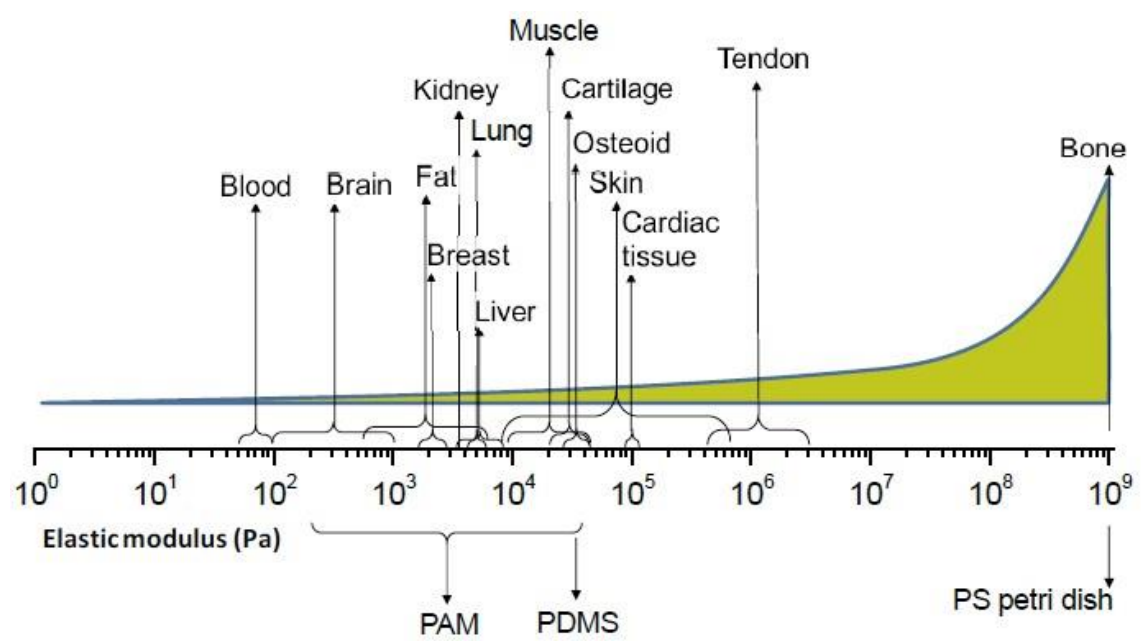

Fig. (5). Stiffness of several different healthy tissues (notice elastic modulus is in logarithmic scale). [4,97-107] On the bottom, typical substrate materials used for cell culturing. Polyacrylamide (PAM); Polydimethylsiloxane (PDMS); Polystyrene (PS).

\section{COMPOSITE MATERIALS AND HYBRIDS FOR BONE REGENERATION}

In bone regeneration since the 80s [114], composite materials are usually made by associating an organic phase with an inorganic one. This combination is an interesting approach for scaffold fabrication, as the nature of the selected constituents resembles the structure of natural bone. The organic part can mimic the collagen and the glycosaminoglycans (GAG) present in the extracellular matrix, while the inorganic one can mimic the bone mineral phase. The aim is that the global properties of the scaffold are supported by both constituents $[115,116]$. A typical example of a composite is a scaffold prepared by incorporating hydroxyapatite (HA) granules or fibers in a polymeric matrix [117-122]. Such studies reveal, how- ever, that the contents of the inorganic and organic phases directly influence the bioactivity and mechanical properties of the scaffolds. In many cases, a template that is efficiently bioactive often has weak mechanical properties [93]. Thus, a compromise should be found when developing composites in order to obtain a suitable balance between the two properties, considering too that inorganic compound shape, size, dispersion, orientation and mechanical features also play a role [115]. Furthermore, the scaffolds should have an appropriate structure with interconnected pores to enable cell attachment, migration into the scaffolds, and fluid and blood vessel infiltration [15, 123, 124]. Interestingly, composites can be shaped with diverse architectures and with different porosity $[15,90]$. This is possible thanks to the various processing technologies currently available, such as solvent-casting and particulate leaching techniques, gas foaming, rapid prototyping and electrospinning.

Another parameter that is also crucial to the scaffold's final properties is the interaction between the organic phase and the inorganic one [125]. Composites commonly prepared with micro-sized inorganic particles by conventional melting processes, for example, do not have a direct interface between their compounds (Fig. 6). This may be caused by the manufacturing process used to prepare the material (such as, for example, a drawing method that may be responsible for the formation of a void between the compounds [93] (Fig. 6a), and/or non-optimal affinity between the compounds [126] (Fig. 6b)). Usually, nanosized inorganic compounds are therefore preferred for preparing composites (nanocomposites), because an enhancement in the interfacial interactions between the phases can be easily achieved [127]. Indeed, the number of inter- faces is increased due to the high surface area provided by nanoscaled compounds, which can lead to 
better control of the mechanical and degradation properties. However, this strategy is not completely optimal, and the probability of crack initiation- propagation may be high due to these numerous interfaces. This may result in an ultimate depreciation of the mechanical properties [115, 128]. To avoid this and also a possible phase segregation [129], polymer/inorganic nanofiller compatibility is often improved by modifying the surface with organic molecules or surfactants $[130,131]$. Despite this, the synergy between the two phases is still often inappropriate for the targeted application because of the heterogeneous degradation of the phases, the rapid loss of the composite mechanical properties, or the inappropriate release rate of ions/monomers from the material [93, 132]. Hence, composite materials with interactions at the molecular or nanometric level (also called hybrid materials) have been developed in order to produce more homogeneous templates with improved properties for bone regeneration (superior mechanical properties, homogeneous degradation and synergistic material). The fabrication of such materials usually involves a common versatile technique: the sol-gel method [133]. This method allows the manipulation of the nanostructure of the materials at the molecular level and the control of the nature of the interfaces. Thus, it is a very powerful tool to develop hybrids.

\subsection{Hybrid Materials}

Hybrids are classified into two categories depending on the nature of the intimate organic-inorganic interface [114, $129,134,135]$. The first family is class I materials, which possess weak inter- actions between constituents (Van der Waals, electrostatic or hydrogen bonding interactions). The second is class II materials, which exhibit strong interactions between components (covalent or ionic bonding). Compared to traditional composites, hybrid scaffolds prepared with weak or strong phase interactions usually pre- sent better properties, but a clear difference in the resulting proper- ties of the scaffold is noted between these two classes of hybrids, however (see a summary in Table 1 ).

\subsubsection{Hybrids Class I}

Hybrid organic-inorganic materials of class I have been extensively investigated up to now for numerous applications. The interpenetration of the organic and inorganic networks constitutes the basis of these materials and explains why class I hybrid scaffolds exhibit improved mechanical and degradation properties when compared to traditional composites. In these materials, the two phases are nanoscopically separated but macroscopically uniform [136].

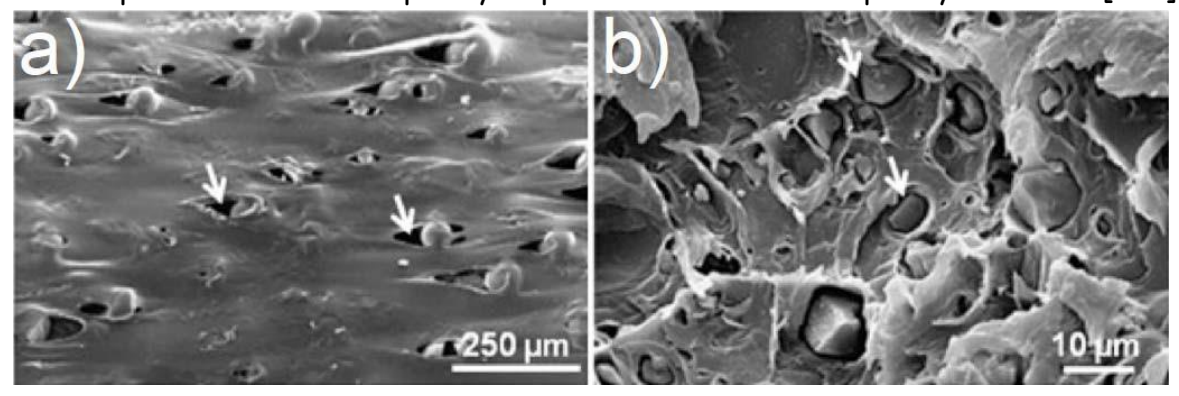

Fig. (6). Typical examples of composites that possess limited intimate interactions between their inorganic constituent (microparticles) and polymeric matrix. Arrows point the presence of voids between the phases (material shown on picture a: extruded and drawn material - material shown on picture b: extruded and compressed material). (picture $a$ is adapted from [93] and picture b from [126] with permissions).

Regarding bone tissue engineering, a representative example is the material developed by Martin et al. in 2004 [19]. Polyvinyl alcohol (PVA) was chosen for the organic part and bioactive glass for the inorganic one. They incorporated PVA during the synthesis of the bioactive glass, which was prepared by the sol-gel method. After gelation of this hybrid sol and an aging-drying process, class I hybrid monoliths were obtained. The study revealed that by control- ling the experimental conditions, crack-free monoliths could be produced. The degradation as well as the bioactivity of the materials could be also tailored by changing, for example, the content of PVA, or adding extra-compounds in the initial glass composition

$\left(\mathrm{P}_{2} \mathrm{O}_{5}\right.$ in $\mathrm{CaO}-\mathrm{SiO}_{2}$ system). In their study no mechanical tests were performed, but another report by Landry et al. showed that organic- inorganic materials prepared by the in situ polymerization of silanes (tetraethylorthosilicate TEOS) in polymers resulted in materials with enhanced mechanical properties [137]. This was attributed to the nature of the interactions between the two phases: the hydrogen bonds formed between the residual hydroxyls of the hydrolyzed TEOS molecules and the ones in the polymer, which acted as crosslinkers [138]. However, this kind of bonding is rather weak and is not stable in aqueous medium, as the water molecules may easily separate the chains [139]. For this reason, the degree of crosslinking and interpenetration of the phases is very important. If the nature of the precursors is not properly considered, and if the conditions of the hydrolysis reaction are not well controlled, the crosslinking and phase interpenetration may not be sufficient to tailor the degradation of the material efficiently. In the case of a fast 
degradation might not be suitable to support bioactivity, for example [19]. Another drawback for the production of these materials is the phase separation that might occur due to incompatibilities be- tween the phases. Once again, reaction conditions such as temperature and $\mathrm{pH}$ are of paramount importance to accomplish a homogeneous material, and this should be precisely controlled [137]. Al- though they do have some drawbacks, class I materials are promising considering the overall properties they can exhibit if their de- sign is properly tailored.

The last example has been published recently. Similar to ormosils, ormoglasses are organic modified glasses; in other words, organometallic oligomer or polymer chains with no apparent order. They share some properties of pure inorganic compounds, such as hydrophylicity and ion release, but offer further features such as a positive charge, which improves interaction with some negative biodegradable polymers such as PLA, and more flexibility [140]. The calcium and phosphate included in their formulations are linked to the ormoglass rather than being encapsulated as a salt, suggesting that a more sustained release to enhance osteo- and angiogenesis can be achieved.

\subsubsection{Hybrids Class II}

An increasing effort has been made in recent years to produce class II materials to overcome the problems resulting from weak interactions between the material phases. The aim is to produce scaffolds with a good stability and a good performance under physiological conditions. Nevertheless, such materials are difficult to produce, and few involving biocompatible and biodegradable polymers have been reported in the bone regeneration literature. Normally, they imply the use of coupling agents to functionalize the polymer in order to covalently link the polymer to the inorganic part (a pure silica network or silica network with incorporated calcium and CaP-ormoglasses) [141-144]. Considering that there are only a few examples of class II hybrid materials in the literature and that they show a high promising potential for the field, each one is briefly presented here.

The first family of materials (disc shape) was developed by Tian et al. in the 90s [141]. This material was a polycaprolactone $(P C L)$ /silica hybrid prepared by the sol-gel method, in which $P C L$ was intimately incorporated into a silica network produced by condensation of TEOS. The reaction consisted of the end-capping of hydroxyl PCL with isocyanatopropyltriethoxysilane (IPTES). The terminal hydroxyl groups of the polymer reacted with the isocyanate group of IPTES to form a urethane linkage, creating an IP- TES end-capped PCL. After the substitution of the ethoxy ligands of IPTES by hydroxyl groups (hydrolysis), IPTES end-capped PCL condensated and linked to hydrolyzed TEOS molecules. As a result, a silica network containing polymeric fragments was created, in which IPTES acted as an intermediate covalent linker between the two phases. The reaction extent was mainly controlled by the molecular weight of the PCL as the length of the PCL chains directly influenced the number of available sites for reaction [145]. Consequently, the shorter the chains, the higher the number of available reactive terminal groups, and the higher the end-capping potential. Apart from the covalent bonding, these hybrids were shown to be packed due to hydrogen bondings: PCL ester groups interacted with the residual hydrolyzed ethoxyl groups of the silica network [145]. These two types of interactions contributed to the good stability of the polymeric phase in hybrids in comparison to pure PCL [145]. In addition, according to preliminary tests [146], it was shown that these hybrids were also a suitable support for fibroblast cell cultures.

Several years later, Rhee et al. incorporated calcium $\left(\mathrm{CaCl}_{2}\right)$ in the system, with the aim of improving the hybrids' bioactivity [147- 149]. This was a very interesting idea, as calcium ions $\left(\mathrm{Ca}^{2+}\right)$ play an important role in the bioactivity efficiency of materials and the osteogenesis process. Later, Rhee published a more detailed study in which he assessed the bone-like apatite-forming ability of this end-capped PCL/silica/calcium material depending on the PCL content in the hybrids [150]. Hybrids containing the lowest PCL content exhibited the best bioactive properties. This was explained by the presence of a higher number of silanol groups in the silica phase for the low PCL content hybrids and a stronger release of $\mathrm{Ca}^{2+}$ into the simulated body fluid (SBF) solution $[148,150,151]$. Indeed, it is well reported that silanols act as nucleation sites for apatite crystals, and $\mathrm{Ca}^{2+}$ ions released in the surrounding medium contribute to the supersaturation of the fluids and the deposition of a calcium phosphate precipitate $[152,153]$. The study showed that the PCL content also affected the mechanical properties of the materials, but all the materials possessed tensile strengths and Young's moduli in the range of trabecular bone. Moreover, in vivo tests revealed that the material directly induced bone formation on the surface of the scaffold without creating any fibrous tissue [151].

The second family of materials (porous) was developed by Poologasundarampillai et al. in 2010 [142]. They functionalized a biopolymer, poly(y-glutamic acid) (yPGA), with glycidoxypropyltrimethoxysilane (GPTMS) and used TEOS to create the inorganic network, adding calcium into it $\left(\mathrm{CaCl}_{2}\right)$. Although synthetic polymers such as $P C L$ or $P G A$ degrade by random chain scissions from the bulk and rapidly affect the mechanical properties of the material, the natural yPGA degrades enzymatically from the surface. This means that the bulk of the material can maintain its mechanical properties as long as water does not infiltrate the matrix and catalyze the inner degradation. It was thus expected that the use of yPGA 
would slow down the loss of the scaffold's mechanical integrity. But the degradation process is a complicated phenomenon, whose rate and mechanism is influenced by numerous factors (porosity, hydrophilicity, $\mathrm{pH}$ of surrounding fluid, etc). As no direct study has been performed to assess the loss of mechanical properties and the role of yPGA, it is not possible, however, to certify that YPGA is an effective compound for better control of the material degradation of class II hybrids.

However, one of their complementary studies revealed the role of the degree of crosslinking in the dissolution time of the polymer [154]. Hybrid materials with a high degree of crosslinking exhibited a slower polymer release than ones prepared with a lower covalent coupling. As reported in their first synthesis study, the coupling of the two materials can be tailored by the amount of coupling agent used for reaction: a higher proportion of coupling agent resulted in an increase in the organic/inorganic interactions. On the other hand, they demonstrated that the amount of solvent used in such reactions impacts the reaction rate, the nanostructure and the nanoporosity of the materials. As for the end-capped $\mathrm{PCL} /$ silica/calcium material, these hybrids exhibited good bioactivity, as calcium ions have been pointed out as essential for the formation of the hydroxyl carbonated apatite. The incorporation of calcium in the network was there- fore required to promote bioactivity. Knowing that a high degree of crosslinking in the hybrids leads to more compact structures and consequently a relatively slow dissolution rate of calcium, the working reaction conditions should be carefully selected in order to reach a proper bioactivity. About mechanical properties, compresive mechanical tests demonstrated that the toughness of the hybrids was improved, in comparison to glass alone. Finally, cellular assays (live/dead test) showed that Saos-2 [155] lineage cells attached and spread on the material surface without suffering any cytotoxic effects.

The third family of materials (foamed structure) was developed by Mahony et al. in 2010 [143]. It is also prepared with a bio- polymer (gelatin) and (3-Glycidoxypropyl)methyldiethoxysilane (GPTMS). TEOS was also used to form the silica network but the materials did not contain calcium. The main aim of this study was to demonstrate that tough materials could be created by preparing class II materials. As for the previous materials, the study showed that the percentage of gelatin and degree of crosslinking affected the mechanical properties of the scaffolds. The degree of porosity was influenced by the concentration of surfactant used during the material foaming. This globally impacted the mechanical strength of the scaffolds. All materials produced were considered stiff substrates, based on the approximate stiffness of various tissues. In addition, they had remarkable elastic properties and tailorable dis- solution properties. Finally, according to cell morphological observations (mesenchymal stem cells (MSCs)), the materials were shown to be biocompatible and non-cytotoxic independently of the precursor reagent content or the chemical control performed on the reactions (degree of crosslinking and amount of surfactant).

The fourth family of materials (fibrous structure) was recently developed by Sachot et al. [144]. An ormoglass was covalently linked to a degradable polymer (polylactic acid; PLA). Based on the sol-gel method and a succession of surface treatments, they successfully coated hollow electrospun PLA fibers with a silicon CaP based ormoglass (Fig. 7) using aminopropyltriethoxysilane (AP- TES) as coupling agent. This approach allowed a direct interaction of the bioactive phase with cells, as well as controlled release of the ions. Rat MSCs cultured on these fibers showed good cell spreading and excellent interactions with the material. Moreover, the coated electrospun mat was remarkably flexible [144]. In addition, the protocol can be transferred to other structures and ormoglasses, thus allowing the fabrication of various materials with well-defined features and offering a large range of possibilities for the development of scaffolds for numerous applications.

Although the hybrids described above seem to be the only class II materials found in the literature, it should be noted that other materials may also emerge in the next few years. Maeda et al., for example, have already achieved the first step of polymer functionalization with PLA and APTES as coupling agent [156]. However, they did not exploit this finding to create a real organic/inorganic material in which the functionalized polymer is intimately incorporated in a silica network; rather, the material was simply formed through the reaction of functionalized PLA chains with other functionalized PLA chains. No reagent such as TEOS was used to intro- duce a high content of inorganic network in the hybrid. 


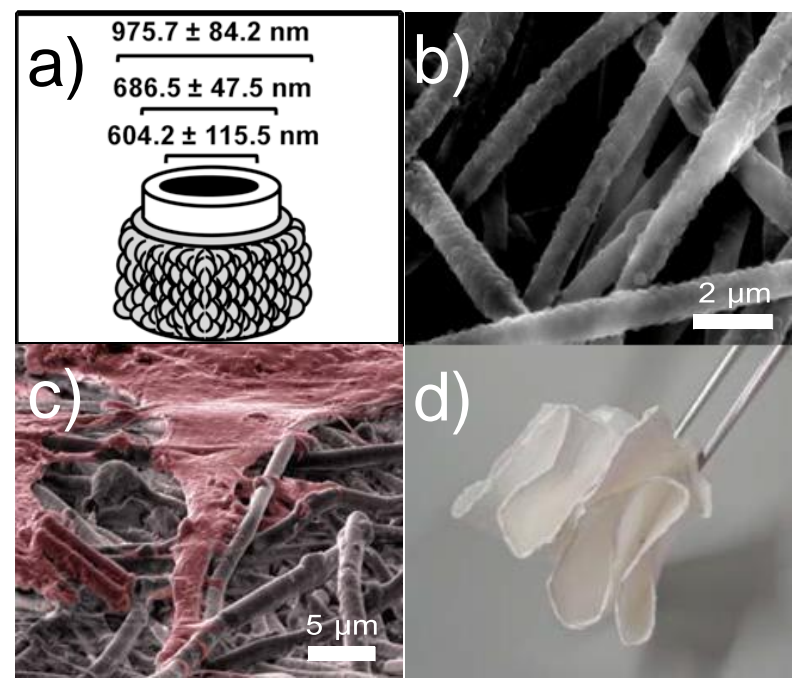

Fig. (7). Ormoglass coated fibers adapted from [144] with permission a) average diameters of hollow nanofibers coated with ormoglass. b) FE-SEM image of their surface. c) rMSCs adhered to coated fibers. d) flexibility of the tissue at the macroscale.

Therefore, the inorganic content was restricted to the quantity of APTES molecules efficiently linked to the PLA chains, and only molecular weight was a valid variable to modulate final results. From a general point of view, this material could be considered as a class II hybrid because it possesses a strong covalent bond between its organic and inorganic phases. However, it does not exactly fit into the category, because no inorganic network was really introduced in the material (except the part of the APTES organosilane). For this material, classification is rather subjective and controversial [139, 157]. Some scientists might already consider it a class II material, while others may not. In any case, such functionalized polymers might be the starting point for the production of additional class II hybrids in the future, as it has been the case for the GPTMS functionalized gelatin prepared by Ren et al. $[157,158]$ in 2001 and the subsequent work described above, performed by Mahony et al. in 2010.

Finally, there are several approaches involving strong mineralization of porous constructs such as hydrogels. One example of innovative alternatives are the scaffolds developed by Douglas et al. [159] They mineralized porous constructs by enzymatic routes (alkaline phosphatase (ALP)-induced enzymatic mineralization) in- stead of conventional SBF immersion. In this way, they achieved the deposition not only of CaP but also magnesium phosphate (MgP), a well-known CaSR agonist $[87,160]$. The results were crystalline and amorphous calcium deficient hydroxyapatite (CDHA) mineralized gellan gum (GG) mimicking natural bone.

Further efforts should be done in order to have the possibility to perform clinical studies once in vivo models and relevant results are trustworthy, and adapted to the nature of these types of nanostructured hybrid scaffolds. This step however, as far authors know, still did not arrive.

\section{COMMON SCAFFOLD PROCESSING METHODS}

\subsection{Electrospinning}

Among the various fabrication methods available to produce 3D scaffolds, electrospinning is one of the most used techniques nowadays, in spite of its inherent difficulties to create macropores for cell migration. It is based on electrostatic principles and enables the deposition of micro and nano-scaled fibers. The main benefit of producing electrospun fibrous substrates is being able to mimic the nanofibrous structure of the collagen ECM [9, 22, 161]. It is, moreover, a cost-effective technique that does not require sophisticated equipment and which can be used with an impressive variety of compounds $[161,162]$. The set-up consists of a syringe pump, a voltage source and a metallic collector (Fig. 8a). The principle be- hind the formation of fibers relies on the competition between the electrostatic forces formed in a polymeric slurry (melt [163] or solution [22]) when it is subjected to a high voltage, and its surface tension. When a voltage on the tip of the syringe is sufficiently increased up to a critical point, repulsive forces overcome the surface tension and a liquid jet rises from the drop (the appearance of a Taylor cone [164]). The further the jet travels from the drop, the thinner and more elongated it becomes. This occurs because of the instability of the jet, which starts to whip and then bend and stretch [165-167] (Fig. 8b). During this whipping process, the solvent evaporates, and solidification of the jet occurs. Fibers are then collected on a grounded metallic support. The flying time of the jet should thus be long enough to enable its complete drying out. Fibers are deposited either as random or aligned mats, by using immobile or rotary collectors respectively $[168,169]$. 


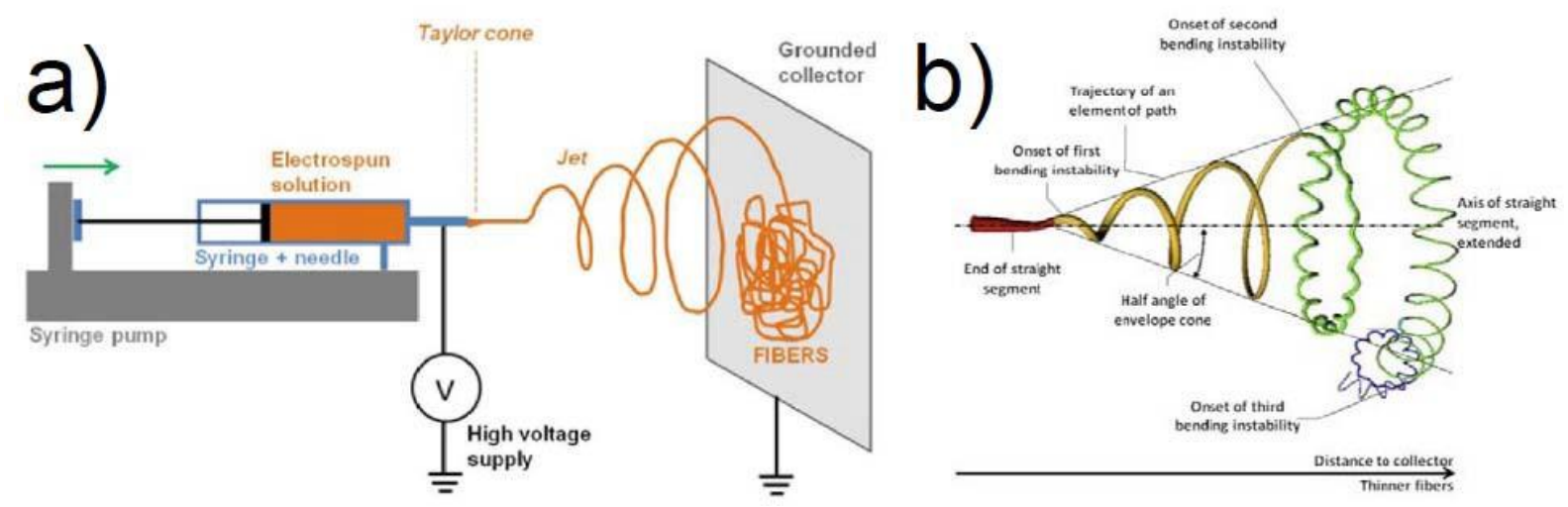

Fig. (8). a) Scheme representing the electrospinning set-up. b) Path of an electrospinning jet that undergoes bending instabilities, solvent evaporation and slimming. (image adapted from [167] with permission).

As regards biological concerns, composite electrospun fibers are the most interesting materials. In fact, bioactive compounds are generally added in the polymeric solution to provide bioactivity to the organic substrate [170]. To do so, bioactive nanoparticles are frequently used. They are incorporated in the polymeric solution before starting the electrospinning. Typically, these nanoparticles are hydroxyapatite or silica xerogels [171-173]. Due to their high surfaceto-volume ratio, these composites usually show good cellular adhesion and activity [22, 162, 174]. As explained previously, the nanotexture (i.e nano-roughness induced by the nanosized fibers) that provides such electrospun fibers is particularly attractive for cells. They are also particularly interesting as they have been demonstrated to promote mineralization. However, this is not al- ways the case for all of the nanocomposites. Some possess limited bioactivity or cellular responses due to a common critical problem: the bioactive phase is embedded in the polymer. Consequently, at early stages this phase is not detected by cells, nor does it contribute to the supersaturation of bioactive ions at the interface of the biomaterial and the biological environment, a mechanism necessary to induce calcium-phosphate precipitation which is also involved in cell signaling [77]. An interesting study by Tong et al. demonstrated that the exposition of the particles can be controlled by changing the size of the nanoparticles and by precisely controlling the experimental parameters of the electrospinning process using an in situ coupled ultrasonic probe for dispersion of the nanoparticles [92]. However, even though researchers seem to be aware that the encapsulation of the bioactive phase is a critical issue, very few studies that focus on that problem are found in the literature. To overcome this challenge, as well as the limitations related to conventional composites (inhomogeneous degradation rate of the com- pounds, very low or inexistent cohesion between them and limited strength), hybrid organic-inorganic fibers prepared by the sol-gel method have attracted more interest in the last five years. Song and coworkers were, for example, some of the first to introduce this concept in bone tissue engineering and electrospinning [175]. In 2008, they reported the development of gelatin-siloxane nanofibers produced with intimate interactions between their compounds (hydrogen bonding). The siloxane introduced in the gelatin acted as a bridging agent for the polymer chains and resulted in a crosslinking effect. The fibers exhibited a good stability and were able to form bone mineral, and were also able to efficiently support cell adhesion, spreading and proliferation, as well as enhancing osteoblastic activity. This hybrid appeared to be a promising material for bone regeneration. This study thus highlighted the potential of the sol-gel technology to prepare hybrid scaffolds using electrospinning and the necessity to produce a synergic hybrid blend. In this way, scaffolds with remarkable properties can be produced. However, in comparison to the nanocomposites approach, hybrid fibers have not attracted the attention of many research groups.

\subsection{Rapid Prototyping}

Rapid prototyping (RP), or solid freeform techniques, involves several methods for scaffold processing and have become very popular in bone regeneration in recent years. RP is one of the few methods that can provide similar mechanical properties to trabecular bone while maintaining a high level of porosity. This technique basically consists of the physical reproduction of a computer- generated design [176] and the depositing of a precursor slurry. The deposited wall can be the result of a melt or a polymer solution containing a dispersed inorganic phase, with the dispersion of an inorganic phase into a polymer matrix being the most common approach for RP to date. However, this strategy presents drawbacks similar to the slurries prepared for electrospinning, i.e. phase masking, heterogeneous dispersions, poor polymer/inorganic phase interaction. Nevertheless, the advantage of rapid prototyping is the fabrication of scaffolds with a higher mechanical resistance and macroporosity (in comparison to electrospinning). Minimum wall thicknesses are at around the tens of microns, which can also induced an undesired diffusion-controlled degradation. Recently, RP has been combined 
with electrospinning, which seems to give good results [177] highlighting thus the potential of associating different techniques together.

\subsection{Solvent Casting/Particle Leaching}

This simple technique has had good results in tissue engineering, as it combines a good interconnection between pores, and high porosity (around 90-95\%); however, the resulting mechanical properties are far to be similar to bone. It basically consists of the dispersion of an inorganic phase in a polymer solution, which also has a homogeneously dispersed aqueoussoluble porogen. Once the solvent is evaporated after casting the slurry into molds, the solid piece is immersed in water to dissolve the porogen and produce pores [80]. However, the wetting of the particles should be improved for optimized mechanical properties. Several approaches can be found in the literature, with excellent results [170, 178].

\subsection{Freeze-drying}

Freeze-drying, or lyophilization, is a way of producing porous scaffolds that involves the sublimation of the solvent in a polymer solution through the decrease of temperature and pressure under the triple point. With this process, a high level of porosity is achieved [170], and this versatile process can easily be tuned. For example, unidirectional freezedrying allows the texture and alignment of porosity, improving pore interconnection [179]. The amount of porosity needs to be higher than $95 \%$ and mechanical properties are, as in some types of bone, anisotropic. In this case, to produce hybrid materials, a slurry solution of polymer and an inorganic constituent are usually uniaxially frozen using a thermal gradient with liquid nitrogen, and then placed in high vacuum for hours or days. Combinations are multiple, especially in bone regeneration [180].

\subsection{Foaming}

Foaming, one of the most common methods to produce macro- porous scaffolds, uses chemical (surfactants) or physical porogens $\left(\mathrm{H}_{2} \mathrm{O}_{2}\right.$, mixer, supercritical $\mathrm{CO}_{2}$ [181]) to improve cell migration. However, the problem of pore connection still needs to be solved, as the neck is usually not big enough for cell migration and colonization. Several examples can be found involving class I hybrid embedded in a polymer matrix, with uneven results [182, 183]. Another problem is the lack of mechanical resistance, which is inherent to the level of porosity, but this can be solved by polymer reinforcement [118].

Table 1. Summary of different hybrid scaffolds for bone regeneration.

\begin{tabular}{|c|c|c|c|c|c|}
\hline $\begin{array}{l}\mathrm{CaO}-\mathrm{SiO}_{2} \\
\mathrm{CaO}-\mathrm{SiO}_{2-}\end{array}$ & Polyvinyl alcohol (PVA) & I & Crack-free monoliths can be produced & Casting & [19] \\
\hline $\begin{array}{l}\text { In situ polymerized } \\
\text { silane }\end{array}$ & $\begin{array}{c}\text { poly(methyl methacrylate) } \\
\text { (PMMA) poly (vinyl acetate), } \\
\text { poly }\end{array}$ & I & $\begin{array}{c}\text { Enhance mechanical properties } \\
\text { and degradation }\end{array}$ & Casting & {$[137,138]$} \\
\hline Si-Ca-P ormoglass & Polylactic acid (PLA) & I & $\begin{array}{l}\text { Introduction of } \mathrm{Ca} \text { and } \mathrm{P} \text { in an } \\
\text { organometallic network with similar }\end{array}$ & Electrospinning & [140] \\
\hline $\begin{array}{l}\text { Hydroxiapatite } \\
\qquad(H A)\end{array}$ & $\begin{array}{l}\text { Polylactic acid (PLA) and } \\
\text { collagen type I }\end{array}$ & I & $\begin{array}{l}\text { Enhance proliferation and } \\
\text { mineralitzation in human fetal }\end{array}$ & Electrospinning & [171] \\
\hline Siloxane and $\mathrm{CaCl}_{2}$ & gelatin & I & $\begin{array}{l}\text { First organometallic network being } \\
\text { combined with a polymer. Better } \\
\text { stability than pure gelatin fibers. }\end{array}$ & Electrospinning & [175] \\
\hline HA nanoparticles & PLA & I & $\begin{array}{l}91-96 \% \text { of interconnected porosity } \\
\text { with a maximum compressive modulus }\end{array}$ & $\begin{array}{l}\text { Supercriti } \\
\text { cal }\end{array}$ & [181] \\
\hline
\end{tabular}




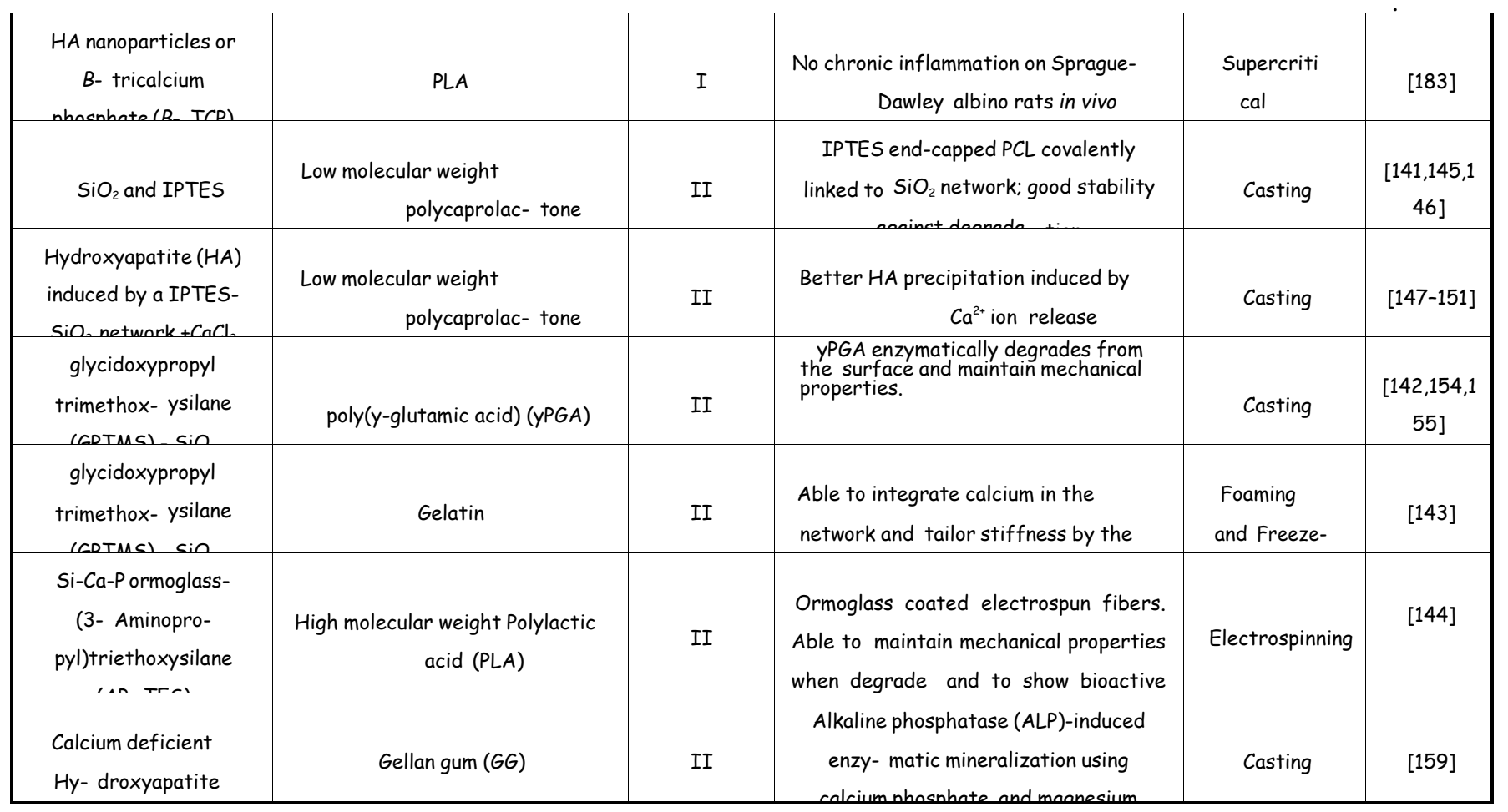

\section{SOFT TISSUES}

The incorporation of hybrid materials in tissues other than bone is still at an embryonic stage (see Table 2), but skin is one tissue whose researchers are beginning to incorporate hybrid materials into their studies [184]. Skin is not a simple structure, but rather a very hierarchical distribution of several strata, which covers and protects the body; as with bone, skin wounds are sometimes too big for the body to repair by itself. The epidermis, formed by flattened epithelial cells distributed in layers, forms the outer part of the organ. The dermis, just under the epidermis, is basically composed of fibroblasts and dense connective tissue. Here biological entities such as receptors, hair follicles, nerves, blood vessels, muscles, ligaments and different glands can be found. However, the first materials used for major skin damage do not aspire to regenerate such a complex system. The minimum requirements for a regenerative wound dressing are: a proper seal to avoid the entry of bacteria, and capability to allow the diffusion of oxygen, water, nutrients and residues. Applications for such wound dressings include serious burns, ulcers (diabetic or pressure-derived) or traumatic accidents [185]. Currently, the options available are mainly salts dispersed in a polymer matrix or forming hybrid structures that act as crosslinkers of the same polymer matrix, such as alginates. Antibacterial agents can also be incorporated into the material to prevent infection; one example is alginates mixed with chitosan and silver nanoparticles acting as the antibacterial agent [186]. Another interesting approach is to enhance the bioavailability of thrombin, a coagulation agent particularly relevant in skin care as it is the result of the hemostatic response and is essential for the conversion of fibrinogen to fibrin, a process involved in wound regeneration, by conjugation with iron oxide nanoparticles ( $y$-Fe $\mathrm{O}_{3}$ ) [187]. The acceleration of the regenerative process was confirmed by analyzing the tensile resistance of wounds in vivo. Other materials such as nitrite-containing glassy ormosils (siloxanes) mixed with chitosan and polyethilenglycol (PEG) provide efficient nitric oxide (NO) release matrices. NO has been demonstrated to be an efficient anti-bacterial agent and vasoactivity modulator as well as angiogenic stimulator, making it a good promoter of wound healing [188]. In addition, and similarly to bone regeneration, collagen-supporting calcium phosphate nanoparticles have been shown to be efficient agents in treat wound healing thanks to their controlled release of ions [189].

Table 2. Summary of different hybrid scaffolds for soft tissue regeneration.

\begin{tabular}{|c|c|c|c|c|c|c|}
\hline Inorganic Phase & Organic Phase & Hybrid Class & Relevant Features & Process Method \\
\hline \multicolumn{7}{|c|}{ Refs. } \\
\hline Silver nanoparticles & Chitosan & I & Antibacterial properties & Freeze-drying & {$[186]$} \\
\hline
\end{tabular}




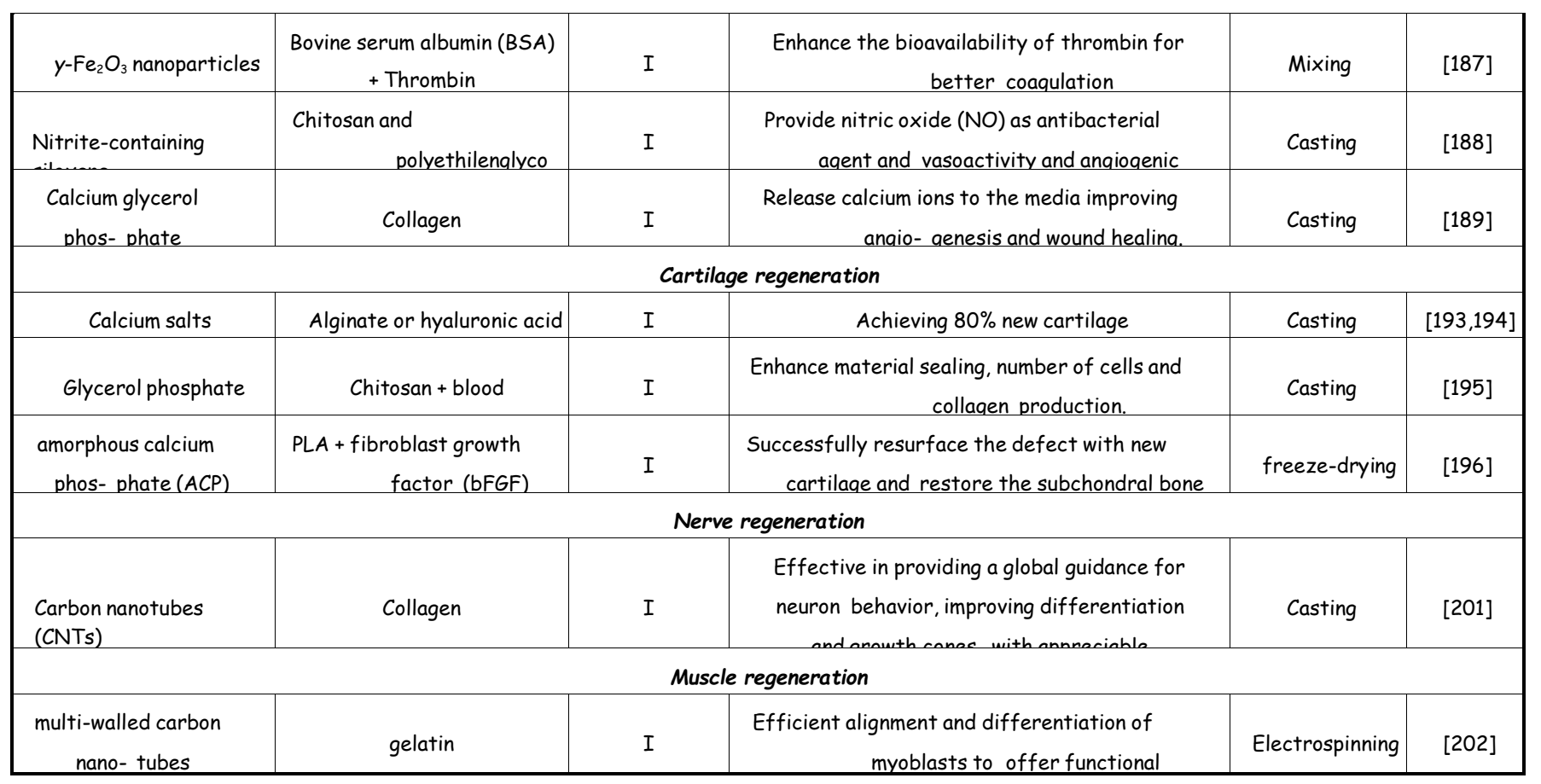

Cartilage is considered a non-vascular tissue, as the blood sup- ply is limited, and nerve and lymphatic vessels are scarce; in this way it shares some similarity with the osteoid. It is also a tissue that is not easily regenerated by itself. The human body involves three types of cartilage: elastic, fibrous, and hyaline (articular), which is the one that has invited the most research to date [185, 190, 191]. It is composed by an ECM formed by mainly collagen II fibers ( 60\% dry weight), proteoglycans, and chondrocytes ( $1 \%$ of the total volume distributed in small colonies). It provides a high compressive resistance and a low coefficient of friction, and its functions are related to the smoothing of the synovial joint displacement. The 25- 35\% dry weight component is made up of proteoglycans that include hyaluronic acid, chrondoitin sulphate, keratin sulfate and dermatan sulfate [185].

Arthroplasty is the most common way of replacing a joint, but has associated risks and side effects. The bottom area of the articular cartilage is calcified as protection from the bone [185]. Thus, promising hybrid materials to replace cartilage include those comprising a combination of alginates or hyaluronic acid with calcium salts [192]. Good results were obtained in subcutaneous implantation: 3D shape conservation in mice and sheep, achieving 80\% of new cartilage [193, 194]. Chitosan hydrogels, glycerol phosphate and blood combinations are also an interesting option [195]. Successful resurfacing of the defect with cartilage and restoration of the subchondral bone in rabbit was also achieved by an amorphous CaP/PLA scaffold loaded with basic fibroblast growth factor (bFGF) [196].

Nerve regeneration is another area in which hybrid materials, especially conductive ones, are beginning to be used. The nervous system is extremely complex, and comprises the central nervous system (CNS) and peripheral nervous system (PNS). The functional units are neurons which have lost their ability to divide. In this case, the topography of constructs is focused on aligned shapes. The need for electrical stimulation makes carbon nanotubes (CNTs) and their derivatives an interesting option. For example, a fibrous combination of a biodegradable polymer with CNTs and graphene offer an alternative for the regeneration of the damaged central nervous system (CNS) [197-200], as does a combination with collagen [201].

Muscle tissue engineering needs the fabrication of packed, dense, aligned and mature myotubes [202]. Multi-wall nanotube (MWNT)-gelatin hybrid fibers were produced by electrospinning, and allowed the efficient alignment and differentiation of myoblasts to offer functional myotubes. However, a controversy still exists about the biodegradation of carbon nanotubes and their derivatives [203].

\section{CONCLUSION}

Hybrid materials seem to be valuable systems for bone tissue engineering due to their biodegradable constituents, remarkable bioactivity, good mechanical properties and excellent effi- ciency/cost ratio. The possibility to tune the material structure (foams, discs, fibers or 3D constructs with different porosity) and properties (stiffness, bioactivity, topography) by controlling the material preparation (chemical reactions and reagents contents) is a great advantage, as different applications require materials with different properties, and material design could be adapted to a specific 
application. However, only preliminary assays have been per- formed in vitro and in vivo to demonstrate the biocompatibility of the structures outside the field of bone regeneration. Nanostructuration of hybrid II biomaterials is the natural trend, and few examples are found. No extensive studies seem to have been performed to evaluate in more detail the adhesion, proliferation, differentiation and potential of these scaffolds to trigger specific cellular responses. To further advance towards clinical trials, proper in vitro and in vivo models shall effectively demonstrate that these materi- als efficiently promote osteogenesis (bone) and angiogenesis (bone and rest of tissues). In this way, they could definitely be confirmed as promising grafts, not only for bone regeneration but also for other tissues applications such as skin, nerve, cartilage etc, where they are still in an embryonic state, but growing. But such materials represent a relatively new concept in biomaterials, and their development is just beginning. Other approaches will be performed in the future using diverse polymers, coupling agents and inorganic phases, which will require extensive studies in the next few years to uncover the cellular responses induced by these materials.

\section{CONFLICT OF INTEREST}

The authors confirm that this article content has no conflict of interest.

\section{ACKNOWLEDGEMENTS}

We thank the European Commission (European ERANET pro- ject PI11/03030, NANGIOFRAC), the Spanish Ministry of Economy and Competitiveness (Project MAT2011-29778-C02-01) for funding. O. Castaño also acknowledges the MINECO for the "Ramon y Cajal" contract and the "José Castillejo" mobility allowance.

\section{REFERENCES}

[1] Navarro, M.; Michiardi, A.; Castaño, O.; Planell, J.A. Biomaterials in orthopaedics. J. R. Soc. Interface R. Soc., 2008, 5, 1137-1158.

[2] Dorozhkin, S.V. Calcium orthophosphates and human beings: A historical perspective from the 1770s until 1940. Biomatter, 2012, 2, 53-70.

[3] Holzapfel, B.M.; Reichert, J.C.; Schantz, J.T.; Gbureck, U.; Rackwitz, L.; Nöth, U.; Jakob, F.; Rudert, M.; Groll, J.; Hutmacher, D.W. How smart do biomaterials need to be? A translational science and clinical point of view. Adv. Drug Deliv. Rev., 2013, 65, 581-603.

[4] Engler, A.J.; Sen, S.; Sweeney, H.L.; Discher, D.E. Matrix elasticity directs stem cell lineage specification. Cell, 2006, 126, 677-689.

[5] Bandyopadhyay-ghosh, S. Bone as a collagen-hydroxyapatite composite and its repair. Trends Biomater. Artif. Organs, 2008, 22, 116-124.

[6] Clarke, B. Normal bone anatomy and physiology. Clin. J. Am. Soc. Nephrol., 2008, 3, 131-139.

[7] Rho, J.Y.; Kuhn-Spearing, L.; Zioupos, P. Mechanical properties and the hierarchical structure of bone. Med. Eng. Phys., 1998, 20, 92-102.

[8] Pérez-Amodio, S.; Engel, E. Bone biology and regeneration. Bio-Ceramics with Clin. Appl.; John Wiley \& Sons, Ltd.: $2014 ;$ pp. 315-342.

[9] Olszta, M.J.; Cheng, X.; Jee, S.S.; Kumar, R.; Kim, Y.Y.; Kaufman, M.J.; Douglas, E.P.; Gower, L.B. Bone structure and formation: A new perspective. Mater. Sci. Eng. R Reports, 2007, 58, 77-116.

[10] Stains, J.P.; Civitelli, R. Cell-cell interactions in regulating osteogenesis and osteoblast function. Birth Defects Res. C. Embryo Today, 2005, 75, 72-80,

[11] Stapor, P.C.; Azimi, M.S.; Ahsan, T.; Murfee, W.L. An angiogenesis model for investigating multi-cellular interactions across intact microvascular networks. Am. J. Physiol. Heart Circ. Physiol., 2013, 304, H235-H245.

[12] Saha, K.; Pollock, J.F.; Schaffer, D.V.; Healy, K.E. Designing synthetic materials to control stem cell phenotype. Curr. Opin. Chem. Biol., 2007, 11, 381387.

[13] Provenzano, P.P.; Keely, P.J. Mechanical signaling through the cytoskeleton regulates cell proliferation by coordinated focal adhesion and Rho GTPase signaling. J. Cell Sci., 2011, 124, 1195-1205.

[14] Stevens, M.M.; George, J.H. Exploring and engineering the cell surface interface. Science, 2005, 310, 1135-1138.

[15] Karageorgiou, V.; Kaplan, D. Porosity of 3D biomaterial scaffolds and osteogenesis. Biomaterials, 2005, 26, 5474-5491.

[16] Kuboki, Y.; Takita, H.; Kobayashi, D.; Tsuruga, E.; Inoue, M.; Murata, M.; Nagai, N.; Dohi, Y.; Ohgushi, H. BMP-induced osteogenesis on the surface of hydroxyapatite with geometrically feasible and nonfeasible structures: topology of osteogenesis. J. Biomed. Mater. Res., 1998, 39, 190-199.

[17] Jones, J.R.; Ehrenfried, L.M.; Hench, L.L. Optimising bioactive glass scaffolds for bone tissue engineering. Biomaterials, 2006, 27, 964-973.

[18] Martin, R.A.; Yue, S.; Hanna, J. V: Lee, P.D.; Newport, R.J.; Smith, M.E.; Jones, J.R. Characterizing the hierarchical structures of bioactive sol-gel silicate glass and hybrid scaffolds for bone regeneration. Philos. Trans. R. Soc. A Math. Physical Eng. Sci, 2012, 370, 1422-1443.

[19] Martín, A.I.; Salinas, A.J.; Vallet-Regí, M. Bioactive and degradable organic-inorganic hybrids. J. Eur. Ceram. Soc., 2005, 25, 3533-3538.

[20] Navarro, M.; Ginebra, M.P.; Planell, J.A.; Zeppetelli, S.; Ambrosio, L. Development and cell response of a new biodegradable composite scaffold for guided bone regeneration. J. Mater. Sci. Mater. Med., 2004, 15, 419-422.

[21] Serra, T.; Ortiz-Hernandez, M.; Engel, E.; Planell, J.A.; Navarro, M. Relevance of PEG in PLA-based blends for tissue engineering 3D-printed scaffolds. Mater. Sci. Eng. C, 2014, 38, 55-62.

[22] Jang, J.H.; Castano, O.; Kim, H.W. Electrospun materials as potential platforms for bone tissue engineering. Adv. Drug Deliv. Rev., 2009, 61, 10651083

[23] Tai, H.; Mather, M.L.; Howard, D.; Wang, W.; White, L.J.; Crowe, J.A.; Morgan, S.P.; Chandra, A.; Williams, D.J.; Howdle, S.M.; Shakesheff, K.M. Control of pore size and structure of tissue engineering scaffolds produced by supercritical fluid processing. Eur. Cell. Mater., 2007, 14, 64-77.

[24] Rouquerol, J.; Avnir, D.; Fairbridge, C.W.; Everett, D.H.; Haynes, J.M.; Pernicone, N.; Ramsay, J.D.F.; Sing, K.S.W.; Unger, K.K. Recommendations for the characterization of porous solids. Pure Appl. Chem., 1994, 66, 1739-1758.

[25] Valerio, P.; Guimaráes, M.H.R.; Pereira, M.M.; Leite, M.F.; Goes, A.M. Primary osteoblast cell response to sol-gel derived bioactive glass foams. J. Mater. Sci. Mater. Med., 2005, 16, 851-856.

[26] Xynos, I.D.; Hukkanen, M.V.J.; Batten, J.J.; Buttery, L.D.; Hench, L.L.; Polak, J.M. Bioglass 4555 stimulates osteoblast turnover and enhances bone formation in vitro: Implications and applications for bone tissue engineering. Calcif. Tissue Int., 2000, 67, 321-329.

[27] Sepulveda, P.; Jones, J.R.; Hench, L.L. Bioactive sol-gel foams for tissue repair. J. Biomed. Mater. Res., 2002, 59, 340-348.

[28] Hulbert, S.F.; Young, F.A.; Mathews, R.S.; Klawitter, J.J.; Talbert, C.D.; Stelling, F.H. Potential of ceramic materials as permanently implantable skeletal prostheses. J. Biomed. Mater. Res., 1970, 4, 433-456.

[29] Itälä, A.I.; Ylänen, H.O.; Ekholm, C.: Karlsson, K.H.; Aro, H.T. Pore diameter of more than 100 microm is not requisite for bone ingrowth in rabbits. J. Biomed. Mater. Res., (Applied Biomater.), 2001, 58, 679-683. 
[30] Harris, W.H.; Jasty, M. Bone ingrowth into porous coated canine acetabular replacements: the effect of pore size, apposition, and dislocation. Hip, 1985, 214-234.

[31] O'Brien, F.J.; Harley, B.A.; Yannas, I. V; Gibson, L.J. The effect of pore size on cell adhesion in collagen-GAG scaffolds. Biomaterials, 2005, 26, 433-441.

[32] Murphy, W.L.; Dennis, R.G.; Kileny, J.L.; Mooney, D.J. Salt fusion: An approach to improve pore interconnectivity within tissue engineering scaffolds. Tissue Eng., 2002, 8, 43-52.

[33] Yuan, H.; Kurashina, K.; de Bruijn, J.D.; Li, Y.; de Groot, K.; Zhang, X. A preliminary study on osteoinduction of two kinds of calcium phosphate ceramics. Biomaterials, 1999, 20, 1799-1806.

[34] Lampin, M.; Warocquier-Clérout, R.; Legris, C.; Degrange, M.; Sigot- Luizard, M.F. Correlation between substratum roughness and wettability, cell adhesion, and cell migration. J. Biomed. Mater. Res., 1997, 36, 99-108.

[35] Kawai, N.; Niwa, S.; Sato, M.; Sato, Y.; Suwa, Y.; Ichihara, I. Bone formation by cells from femurs cultured among three-dimensionally arranged hydroxyapatite granules. J. Biomed. Mater. Res., 1997, 37, 1-8.

[36] Dalby, M.J.; Gadegaard, N.; Tare, R.; Andar, A.; Riehle, M.O.; Herzyk, P.; Wilkinson, C.D.W.: Richard O. C. Oreffo. The control of human mesenchymal cell differentiation using nanoscale symmetry and disorder. Nat. Mater., 2007, 6, 997-1003.

[37] Daculsi, G.; LeGeros, R.Z.; Heughebaert, M.; Barbieux, I. Formation of carbonate-apatite crystals after implantation of calcium phosphate ceramics. Calcif. Tissue Int., 1990, 46, 20-27.

[38] Simon, J.L.; Roy, T.D.; Parsons, J.R.; Rekow, E.D.; Thompson, V.P.; Kemnitzer, J.; Ricci, J.L. Engineered cellular response to scaffold architecture in a rabbit trephine defect. J. Biomed. Mater. Res., A, 2003, 66, 275-282.

[39] Brinker, C.J.; Sehgal, R.; Hietala, S.L.; Deshpande, R.; Smith, D.M.; Loy, D.; Ashley, C.S. Sol-gel strategies for controlled porosity inorganic materials. J. Memb. Sci., 1994, 94, 85-102.

[40] Hollister, S.J. Porous scaffold design for tissue engineering. Nat. Mater., 2005, 4, 518-524.

[41] Gadegaard, N.; Dalby, M.J.; Martines, E.; Seunarine, K.; Riehle, M.O.; Curtis, A.S.G.; Wilkinson, C.D.W. Nano patterned surfaces for biomaterial applications. Adv. Sci. Technol., 2006, 53, 107-115.

[42] Lüthen, F.; Lange, R.; Becker, P.; Rychly, J.; Beck, U.; Nebe, J.G.B. The influence of surface roughness of titanium on beta1- and beta3-integrin adhesion and the organization of fibronectin in human osteoblastic cells. Biomaterials, 2005, 26, 2423-2440.

[43] Larsson, C.; Thomsen, P.; Aronsson, B.O.; Rodahl, M.; Lausmaa, J.; Kasemo, B.; Ericson, L.E. Bone response to surface-modified titanium implants: studies on the early tissue response to machined and electropolished implants with different oxide thicknesses. Biomaterials, 1996, 17, 605616.[44] Montanaro, L.; Arciola, C.R.; Campoccia, D.; Cervellati, M. In vitro effects on MG63 osteoblast-like cells following contact with two roughness- differing fluorohydroxyapatite-coated titanium alloys. Biomaterials, 2002, 23, 3651-3659.

[45] Chen, W.; Sun, Y.; Fu, J. Microfabricated nanotopological surfaces for study of adhesion-dependent cell mechanosensitivity. Small, 2013, 9, 81-89.

[46] Chen, J.P.; Su, C.H. Surface modification of electrospun PLLA nanofibers by plasma treatment and cationized gelatin immobilization for cartilage tissue engineering. Acta Biomater., 2011, 7, 234-243.

[47] Grandfield, K.; Engqvist, H. Focused Ion Beam in the Study of Biomaterials and Biological Matter. Adv. Mater. Sci. Eng., 2012, 2012, 1-6.

[48] Flemming, R.G.; Murphy, C.J.; Abrams, G.A.; Goodman, S.L.; Nealey, P.F. Effects of synthetic micro- and nano-structured surfaces on cell behavior. Biomaterials, 1999, 20, 573-588.

[49] Yim, E.K.F.; Pang, S.W.; Leong, K.W. Synthetic nanostructures inducing differentiation of human mesenchymal stem cells into neuronal lineage. Exp. Cell Res., 2007, 313, 1820-1829.

[50] Palin, E.; Liu, H.; Webster, T.J. Mimicking the nanofeatures of bone increases bone-forming cell adhesion and proliferation. Nanotechnology, 2005, 16, 1828-1835.

[51] Lim, J.Y.; Hansen, J.C.; Siedlecki, C.A.; Runt, J.; Donahue, H.J. Human foetal osteoblastic cell response to polymer-demixed nanotopographic interfaces. J.R. Soc. Interface, 2005, 2, 97-108.

[52] Dalby, M.J.; Childs, S.; Riehle, M.O.; Johnstone, H.J.H.; Affrossman, S.; Curtis, A.S.G. Fibroblast reaction to island topography: changes in cytoskeleton and morphology with time. Biomaterials, 2003, 24, 927-935.

[53] Dalby, M.J.; Giannaras, D.; Riehle, M.O.; Gadegaard, N.; Affrossman, S.; Curtis, A.S. Rapid fibroblast adhesion to $27 \mathrm{~nm}$ high polymer demixed nanotopography. Biomaterials, 2004, 25, 77-83.

[54] Dalby, M.J.; Yarwood, S.J.; Riehle, M.O.: Johnstone, H.J.H.; Affrossman, S.; Curtis, A.S. Increasing fibroblast response to materials using nanotopography: morphological and genetic measurements of cell response to 13-nm-high polymer demixed islands. Exp. Cell Res., 2002, 276, 1-9.

[55] Sun, H.; Wirsén, A.; Albertsson, A.C. Electron beam-induced graft polymerization of acrylic acid and immobilization of arginine-glycine- aspartic acidcontaining peptide onto nanopatterned polycaprolactone. Biomacromolecules, 2004, 5, 2275-2280.

[56] Clark, P.; Connolly, P.; Curtis, A.S.G.; Dow, J.A.T.; Wilkinson, C.D.W. Cell guidance by ultrafine topography in vitro. J. Cell Sci., 1991, 99, 73-77.

[57] Gupta, D.; Venugopal, J.; Prabhakaran, M.P.; Dev, V.R.G.; Low, S.; Choon, A.T.; Ramakrishna, S. Aligned and random nanofibrous substrate for the in vitro culture of Schwann cells for neural tissue engineering. Acta Biomater., 2009, 5, 2560-2569.

[58] Xu, C.Y.; Inai, R.; Kotaki, M.; Ramakrishna, S. Aligned biodegradable nanofibrous structure: a potential scaffold for blood vessel engineering. Biomaterials, 2004, 25, 877-886.

[59] Klumpp, D.; Horch Raymund, E.; Beier Justus, P. Tissue engineering of skeletal muscle. Tissue Eng. Tissue Organ Regen., 2007, 13, $2781-2790$.

[60] García, A.J.; Reyes, C.D. The control of human mesenchymal cell differentiation using nanoscale symmetry and disorder. J. Dent. Res., 2005, 84, 407413.

[61] Lee, J.H.; Jung, H.W.; Kang, I.K.; Lee, H.B. Cell behaviour on polymer surfaces with different functional groups. Biomaterials, 1994, 15, 705-711.

[62] Lee, J.H.; Pazk, J.W.; Lee, H.B. Cell adhesion and growth on polymer surfaces with hydroxyl groups prepared by water vapour plasma treatment. Biomaterials, 1991, 12, 443-448.

[63] Curtis, A.S.G.; Forrester, J.V; McInnes, C.; Lawrie, F. Adhesion of cells to polystyrene surfaces. J. Cell Biol., 1983, 97, $1500-1506$.

[64] Arima, $Y_{\text {:; }}$ Iwata, $H$. Effect of wettability and surface functional groups on protein adsorption and cell adhesion using well-defined mixed selfassembled monolayers. Biomaterials, 2007, 28, 3074-3082.

[65] Nakaoka, R.; Yamakoshi, Y.: Isama, K.; Tsuchiya, T. Effects of surface chemistry prepared by self-assembled monolayers on osteoblast behavior. J. Biomed. Mater. Res., A 2010, 94, 524-532.

[66] Webb, K.; Hlady, V.; Tresco, P.A. Relative importance of surface wettability and charged functional groups on NIH 3 T3 fibroblast attachment, spreading, and cytoskeletal organization. J. Biomed. Mater. Res., 1998, 41, 422-430.

[67] Wilson, C.J.; Clegg, R.E.; Leavesley, D.I.; Pearcy, M.J. Mediation of biomaterial-cell interactions by adsorbed proteins: a review. Tissue Eng., 2005, 11, 1-18.

[68] Cai, K.; Frant, M.; Bossert, J.; Hildebrand, G.; Liefeith, K.; Jandt, K.D. Surface functionalized titanium thin films: zeta-potential, protein adsorption and cell proliferation. Colloids Surfaces. B Biointerfaces, 2006, 50, 1-8.

[69] Arima, Y.: Iwata, H. Effects of surface functional groups on protein adsorption and subsequent cell adhesion using self-assembled monolayers. J. Mater. Chem., 2007, 17, 4079-4087.

[70] Punet, X.; Mauchauffé, R.; Giannotti, M.I.; Rodríguez-Cabello, J.C.; Sanz, F.; Engel, E.; Mateos, T.; Miguel, A.; Planell, E.; Josep, A. Enhanced cellmaterial interactions through the biofunctionalization of polymeric surfaces with engineered peptides. Biomacromolecules, $2013,14,2690-2702$. 
[71] Hersel, U.: Dahmen, C.: Kessler, H. RGD modified polymers: Biomaterials for stimulated cell adhesion and beyond. Biomaterials, 2003, 24, 4385-4415.

[72] Delaittre, G.; Greiner, A.M.; Pauloehrl, T.; Bastmeyer, M.; Barner-Kowollik,

C. Chemical approaches to synthetic polymer surface biofunctionalization for targeted cell adhesion using small binding motifs. Soft Matter, 2012, 8, 7323-7347.

[73] Lutolf, M.P.; Hubbell, J.A. Synthetic biomaterials as instructive extracellular microenvironments for morphogenesis in tissue engineering. Nat. Biotech., 2005, 23, 47-55

[74] Massia, S.P.; Hubbell, J.A. An RGD spacing of $440 \mathrm{~nm}$ is sufficient for integrin alphaV beta3-mediated fibroblast spreading and $140 \mathrm{~nm}$ for focal contact and stress fiber formation. J. Cell Biol. 1991, 114, 1089-1100.

[75] Rezania, A.; Healy, K.E. The effect of peptide surface density on mineralization of a matrix deposited by osteogenic cells. J. Biomed. Mater. Res., $2000,52,595-600$.

[76] Lewandowska, K.; Pergament, E.; Sukenik, C.N.; Culp, L.A. Cell-type- specific adhesion mechanisms mediated by fibronectin adsorbed to chemically derivatized substrata. J. Biomed. Mater. Res., 1992, 26, 1343- 1363.

[77] Hoppe, A.; Güldal, N.S.; Boccaccini, A.R. A review of the biological response to ionic dissolution products from bioactive glasses and glass- ceramics. Biomaterials, 2011, 32, 2757-2774.

[78] Hench, L.L. Genetic design of bioactive glass. J. Eur. Ceram. Soc., 2009, 29, 1257-1265.

[79] Gerhardt, L.C.; Widdows, K.L.; Erol, M.M.; Burch, C.W.; Sanz-Herrera, J.A.; Ochoa, I.; Stämpfli, R.; Roqan, I.S.; Gabe, S.; Ansari, T.; Boccaccini,

A.R. The pro-angiogenic properties of multi-functional bioactive glass composite scaffolds. Biomaterials, 2011, 32, 4096-4108.

[80] Charles-Harris, M.; Koch, M.A.; Navarro, M.; Lacroix, D.; Engel, E.; Planell, J.A. A PLA/calcium phosphate degradable composite material for bone tissue engineering: an in vitro study. J. Mater. Sci. Mater. Med., 2008, 19, 1503-1513.

[81] Vila, O.F.; Bagó, J.R.; Navarro, M.; Alieva, M.; Aguilar, E.; Engel, E.; Planell, J.; Rubio, N.; Blanco, J. Calcium phosphate glass improves angiogenesis capacity of poly(lactic acid) scaffolds and stimulates differentiation of adipose tissue-derived mesenchymal stromal cells to the endothelial lineage. J. Biomed. Mater. Res., A, 2013, 101, 932-941.

[82] Day, R.M. Bioactive glass stimulates the secretion of angiogenic growth factors and angiogenesis in vitro. Tissue Eng., 2005, 11, 768-777.

[83] Marie, P.J. The calcium-sensing receptor in bone cells: a potential therapeutic target in osteoporosis. Bone, 2010, 46, 571-576.

[84] Chattopadhyay, N.; Yano, S.; Tfelt-Hansen, J.; Rooney, P.; Kanuparthi, D.; Bandyopadhyay, S.; Ren, X.; Terwilliger, E.; Brown, E.M. Mitogenic action of calcium-sensing receptor on rat calvarial osteoblasts. Endocrinology, 2004, 145, 3451-3462.

[85] Choudhary, S.; Wadhwa, S.; Raisz, L.G.; Alander, C.; Pilbeam, C.C. Extracellular calcium is a potent inducer of cyclo-oxygenase-2 in murine osteoblasts through an ERK signaling pathway. J. Bone Miner. Res., 2003, 18,1813-1824.

[86] Xynos, I.D.; Edgar, A.J.; Buttery, L.D.; Hench, L.L.; Polak, J.M. Gene- expression profiling of human osteoblasts following treatment with the ionic products of Bioglass 4555 dissolution. J. Biomed. Mater. Res., 2001, 55, 151-157.

[87] Aguirre, A.; González, A.; Planell, J.A.; Engel, E. Extracellular calcium modulates in vitro bone marrow-derived Flk-1+CD34+ progenitor cell chemotaxis and differentiation through a calcium-sensing receptor. Biochem. Biophys. Res. Commun., 2010, 393, 156-161.

[88] Maeno, S.; Niki, Y.; Matsumoto, H.; Morioka, H.; Yatabe, T.; Funayama, A.; Toyama, Y.; Taguchi, T.; Tanaka, J. The effect of calcium ion concentration on osteoblast viability, proliferation and differentiation in monolayer and 3D culture. Biomaterials, 2005, 26, 4847-4855.

[89] Navarro, M.; Ginebra, M.; Clément, J.; Martinez, S.; Avila, G.; Planell, J.A. Physicochemical degradation of titania-stabilized soluble phosphate glasses for medical applications. J. Am. Ceram. Soc., 2003, 86, 1342-1352.

[90] Rezwan, K.; Chen, Q.Z.; Blaker, J.J.; Boccaccini, A.R. Biodegradable and bioactive porous polymer/inorganic composite scaffolds for bone tissue engineering. Biomaterials, 2006, 27, 3413-3431.

[91] Navarro, M.; Engel, E.; Planell, J.A.; Amaral, I.; Barbosa, M.; Ginebra, M.P. Surface characterization and cell response of a PLA/CaP glass biodegradable composite material. J. Biomed. Mater. Res., A, 2008, 85A, 477-486.

[92] Tong, H.-W.; Wang, M.; Li, Z.-Y.; Lu, W.W. Electrospinning, characterization and in vitro biological evaluation of nanocomposite fibers containing carbonated hydroxyapatite nanoparticles. Biomed. Mater., 2010, 5, 054111 (13pp).

[93] Niemelä, T.; Niiranen, H.; Kellomäki, M. Self-reinforced composites of bioabsorbable polymer and bioactive glass with different bioactive glass contents. Part II: In vitro degradation. Acta Biomater., 2008, 4, 156-164.

[94] Guilak, F.; Cohen, D.M.; Estes, B.T.; Gimble, J.M.; Liedtke, W.; Chen, C.S. Control of stem cell fate by physical interactions with the extracellular matrix. Cell Stem Cell, 2009, 5, 17-26.

[95] Vogel, V.: Sheetz, M. Local force and geometry sensing regulate cell functions. Nat. Rev. Mol. Cell Biol., 2006, 7, 265-275.

[96] Wozniak, M.A.; Chen, C.S. Mechanotransduction in development: a growing role for contractility. Nat. Rev. Mol. Cell Biol., 2009, 10, 34-43.

[97] Mathur, a B.; Collinsworth, a M.; Reichert, W.M.; Kraus, W.E.; Truskey, G.

a. Endothelial, cardiac muscle and skeletal muscle exhibit different viscous and elastic properties as determined by atomic force microscopy. $J$. Biomech., 2001, 34, 1545-1553.

[98] Stolz, M.; Raiteri, R.; Daniels, A.U.; VanLandingham, M.R.; Baschong, W.; Aebi, U. Dynamic Elastic Modulus of Porcine Articular Cartilage Determined at Two Different Levels of Tissue Organization by Indentation- Type Atomic Force Microscopy. Biophys. J., 2004, 86, 3269-3283.

[99] Solon, J.; Levental, I.; Sengupta, K.; Georges, P.C.; Janmey, P.A. Fibroblast adaptation and stiffness matching to soft elastic substrates. Biophys. J., 2007, 93, 4453-4461.

[100] Cobbold, J.F.L.; Taylor-Robinson, S.D. Liver stiffness values in healthy subjects: implications for clinical practice. J. Hepatol., 2008, 48, 529-531.

[101] Butcher, D.T.; Alliston, T.; Weaver, V.M. A tense situation: Forcing tumour progression. Nat. Rev. Cancer, 2009, 9, 108-122.

[102] Buxboim, A.: Ivanovska, I.L.; Discher, D.E. Matrix elasticity, cytoskeletal forces and physics of the nucleus: how deeply do cells "feel" outside and in? J. Cell Sci., 2010, 123, 297-308.

[103] Tse, J.R.; Engler, A.J. Preparation of hydrogel substrates with tunable mechanical properties. Curr. Protoc. Cell Biol., 2010, Chapter 10, Unit 10.16.

[104] Janmey, P.A.; Miller, R.T. Mechanisms of mechanical signaling in development and disease. J. Cell Sci., 2011, 124, 9-18.

[105] Iivarinen, J.T.; Korhonen, R.K.; Julkunen, P.; Jurvelin, J.S. Experimental and computational analysis of soft tissue stiffness in forearm using a manual indentation device. Med. Eng. Phys., 2011, 33, 1245-1253.

[106] Romanazzo, S.; Forte, G.; Ebara, M.; Uto, K.; Pagliari, S.; Aoyagi, T.; Traversa, E.; Taniguchi, A. Substrate stiffness affects skeletal myoblast differentiation in vitro. Sci. Technol. Adv. Mater., 2012, 13, 064211.

[107] Brum, J.; Bernal, M.; Gennisson, J.L.; Tanter, M. In vivo evaluation of the elastic anisotropy of the human Achilles tendon using shear wave dispersion analysis. Phys. Med. Biol., 2014, 59, 505-523.

[108] Beningo, K.A.; Dembo, M.; Kaverina, I.: Small, J. V: Wang, Y.L. Nascent focal adhesions are responsible for the generation of strong propulsive forces in migrating fibroblasts. J. Cell Biol., 2001, 153, 881-887.

[109] Tamada, M.: Sheetz, M.P.; Sawada, Y. Activation of a signaling cascade by cytoskeleton stretch. Dev. Cell, 2004, 7, 709-718.

[110] Ingber, D.E. Mechanical signaling and the cellular response to extracellular matrix in angiogenesis and cardiovascular physiology. Circ. Res., 2002, 91, 877-887.

[111] Bershadsky, A.D.; Balaban, N.Q.; Geiger, B. Adhesion-dependent cell mechanosensitivity. Annu. Rev. Cell Dev. Biol., 2003, 19, 677-695.

[112] Rowlands, A.S.; George, P.A.; Cooper-White, J.J. Directing osteogenic and myogenic differentiation of MSCs: interplay of stiffness and adhesive ligand presentation. Am. J. Physiol. Cell Physiol., 2008, 295, C1037-C1044. 
[113] Ingber, D.E. Cellular mechanotransduction: putting all the pieces together again. FASEB J. Off. Publ. Fed. Am. Soc. Exp. Biol., 2006, 20, 811-827.

[114] Jones, J.R. Review of bioactive glass: From Hench to hybrids. Acta Biomater., 2013, 9, 4457-4486.

[115] Wang, M. Developing bioactive composite materials for tissue replacement. Biomaterials, 2003, 24, 2133-2151

[116] Kickelbick, G. Introduction to hybrid materials. Hybrid Mater. Synth. Charact. Appl., 2007, pp. 1-48.

[117] Wei, G.; Ma, P.X. Structure and properties of nano-hydroxyapatite/polymer composite scaffolds for bone tissue engineering. Biomaterials, 2004, 25, $4749-4757$.

[118] Thomson, R.C.; Yaszemski, M.J.; Powers, J.M.; Mikos, A.G. Hydroxyapatite fiber reinforced poly(alpha-hydroxy ester) foams for bone regeneration. Biomaterials, 1998, 19, 1935-1943.

[119] Martinez-Valencia, A.B.; Carbajal-De laTorre, G.; Duarte Moller, A.; Esparza-Ponce, H.E.; Espinosa-Medina, M.A. Study of bioactivity, biodegradability and mechanical properties of polyurethane/nano- hydroxyapatite hybrid composites. Int. J. Phys. Sci, 2011, 6, 6681-6691.

[120] Kong, L.; Gao, Y.; Lu, G.; Gong, Y.; Zhao, N.; Zhang, X. A study on the bioactivity of chitosan/nano-hydroxyapatite composite scaffolds for bone tissue engineering. Eur. Polym. J., 2006, 42, 3171-3179.

[121] Rajzer, I.; Castaño, O.; Engel, E.; Planell, J. a. Injectable and fast resorbable calcium phosphate cement for body-setting bone grafts. J. Mater. Sci. Mater. Med., 2010, 21, 2049-2056.

[122] Román, J.; Cabañas, M.V.; Peña, J.; Vallet-Regí, M. Control of the pore architecture in three-dimensional hydroxyapatite-reinforced hydrogel scaffolds. Sci. Technol. Adv. Mater., 2011, 12,045003.

[123] Mastrogiacomo, M.; Scaglione, S.; Martinetti, R.; Dolcini, L.; Beltrame, F.; Cancedda, R.; Quarto, R.; Role of scaffold internal structure on in vivo bone formation in macroporous calcium phosphate bioceramics. Biomaterials, 2006, 27, 3230-3237.

[124] Murphy, C.M.; O'Brien, F.J. Understanding the effect of mean pore size on cell activity in collagen-glycosaminoglycan scaffolds. Cell Adh. Migr., 2010, 4,377-381.

[125] Gan, Y.X. Effect of interface structure on mechanical properties of advanced composite materials. Int. J. Mol. Sci, 2009, 10, 5115-5134.

[126] Blaker, J.J.; Bismarck, A.; Boccaccini, A.R.; Young, A.M.; Nazhat, S.N. Premature degradation of poly(alpha-hydroxyesters) during thermal processing of Bioglass-containing composites. Acta Biomater., 2010, 6, 756-

762.

[127] Misra, S.K.; Mohn, D.; Brunner, T.J.; Stark, W.J.; Philip, S.E.; Roy, I.; Salih, V.; Knowles, J.C.; Boccaccini, A.R. Comparison of nanoscale and microscale bioactive glass on the properties of $\mathrm{P}(3 \mathrm{HB}) /$ Bioglass composites. Biomaterials, 2008, 29, 1750-1761.

[128] Etcheverry, M.; Barbosa, S.E. Glass fiber reinforced polypropylene mechanical properties enhancement by adhesion improvement. Materials (Basel), 2012, 5, 1084-1113.

[129] Mammeri, F.; Le Bourhis, E.; Rozes, L.; Sanchez, C. Mechanical properties of hybrid organic-inorganic materials. J. Mater. Chem., 2005, 15, 3787.

[130] Lee, K.H.; Rhee, S.H. The mechanical properties and bioactivity of poly(methyl methacrylate)/SiO2-CaO nanocomposite. Biomaterials, 2009, 30, 3444-3449.

[131] Liu, A.; Hong, Z.; Zhuang, X.; Chen, X.; Cui, Y.; Liu, Y.; Jing, X. Surface modification of bioactive glass nanoparticles and the mechanical and biological properties of poly(L-lactide) composites. Acta Biomater., 2008, 4, 1005-1015.

[132] Uo, M.; Mizuno, M.; Kuboki, Y.; Makishima, A.; Watari, F. Properties and cytotoxicity of water soluble Na2O-CaO-P2O5 glasses. Biomaterials, 1998, 19, 2277-2284.

[133] Gupta, R.; Kumar, A. Bioactive materials for biomedical applications using sol-gel technology. Biomed. Mater., 2008, 3, 034005(15pp).

[134] Valliant, E.M.; Jones, J.R. Softening bioactive glass for bone regeneration: sol-gel hybrid materials. Soft Matter, 2011, 7, 5083-5095.

[135] Wahl, D.A.; Czernuszka, J.T. Collagen-hydroxyapatite composites for hard tissue repair. Eur. Cell. Mater., 2006, 11, 43-56.

[136] Kickelbick, G. Concepts for the incorporation of inorganic building blocks into organic polymers on a nanoscale. Prog. Polym. Sci, 2003, 28, 83-114.

[137] Landry, C.J..; Coltrain, B.K.; Brady, B.K. In situ polymerization of tetraethoxysilane in poly(methyl methacrylate): morphology and dynamic mechanical properties. Polymer (Guildf), 1992, 33, 1486-1495.

[138] Landry, C.J.; Coltrain, B.K.; Wesson, J.A.; Zumbulyadis, N.; Lippert, J.L. In situ polymerization of tetraethoxysilane in polymers: chemical nature of the interactions. Polymer (Guildf), 1992, 33, 1496-1506.

[139] Valliant, E.M.; Jones, J.R. Softening bioactive glass for bone regeneration: sol-gel hybrid materials. Soft Matter, 2011, 7, 5083-5095.

[140] Castano, O.; Sachot, N.; Xuriguera, E.; Engel, E.; Planell, J.A.; Park, J.H.; Jin, G.Z.; Kim, T.H.; Kim, J.H.; Kim, H.W. Angiogenesis in bone regeneration: tailored calcium release in hybrid fibrous scaffolds. ACS Appl. Mater. Interfaces, 2014, 6, 7512-7522.

[141] Tian, D.; Dubois, P.; Jeromet, R. A new poly(epsilon-caprolactone) containing hybrid ceramer prepared by the sol-gel process. Polymer (Guildf), 1996, 37, 3983-3987.

[142] Poologasundarampillai, G.; Ionescu, C.; Tsigkou, O.; Murugesan, M.; Hill, R.G.; Stevens, M.M.; Hanna, J.V.: Smith, M.E.; Jones, J.R. Synthesis of bioactive class II poly(y-glutamic acid)/silica hybrids for bone regeneration. J. Mater. Chem., 2010, 20, 8952-8961.

[143] Mahony, O.; Tsigkou, O.: Ionescu, C.; Minelli, C.; Ling, L.; Hanly, R.; Smith, M.E.; Stevens, M.M.; Jones, J.R. Silica-gelatin hybrids with tailorable degradation and mechanical properties for tissue regeneration. Adv. Funct. Mater., 2010, 20, 3835-3845.

[144] Sachot, N.; Castaño, O.; Mateos-timoneda, M.A.; Engel, E.; Planell, J.A. Hierarchically engineered fibrous scaffolds for bone regeneration. J. R. Soc. Interface, 2013, 10, 20130684.

[145] Tian, D.; Dubois, P.H.; Jerome, R. Biodegradable and biocompatible inorganic - organic hybrid materials. I. synthesis and characterization. J. Polym. Sci. Part A Polym. Chem., 1997, 35, 2295-2309.

[146] Tian, D.; Dubois, P.; Grandfils, C.; Robert, J.; Viville, P.; Lazzaroni, R.; Bredas, J.L.; Leprince, P. A novel biodegradable and biocompatible ceramer prepared by the sol-gel process. Chem. Mater., 1997, 9, 871-874.

[147] Rhee, S.H.; Choi, J.Y.; Kim, H.M. Preparation of a bioactive and degradable poly(s-caprolactone)/silica hybrid through a sol-gel method. Biomaterials, $2002,23,4915-4921$.

[148] Rhee, S.H. Effect of calcium salt content in the poly(s-caprolactone)/silica nanocomposite on the nucleation and growth behavior of apatite layer. J. Biomed. Mater. Res., A, 2003, 67, 1131-1138.

[149] Rhee, S.H.; Lee, Y.K.; Lim, B.S.; Yoo, J.J.; Kim, H.J. Evaluation of a novel poly(s-caprolactone)-organosiloxane hybrid material for the potential application as a bioactive and degradable bone substitute. Biomacromolecules, 2004, 5, 1575-1579.

[150] Rhee, S.H. Bone-like apatite-forming ability and mechanical properties of poly(s-caprolactone)/silica hybrid as a function of poly(s-caprolactone) content. Biomaterials, 2004, 25, 1167-1175.

[151] Yoo, J.J.; Lee, J.E.; Kim, H.J.; Kim, S.; Lim, J.H.; Lee, S.J.; Lee, J.II.; Lee, Y.K.; Lim, B.S.; Rhee, S.H. Comparative in vitro and in vivo studies using a bioactive poly(s-caprolactone)-organosiloxane nanohybrid containing calcium salt. J. Biomed. Mater. Res., Part B Appl. Biomater., 2007, 83B, 189-198.

[152] Ohtsuki, C.: Kokubo, T.; Yamamuro, T. Mechanism of apatite formation on CaO-SiO2-P205 glasses in a simulated body fluid. J. Non. Cryst. Solids, $1992,143,84-92$.

[153] Kokubo, T.; Kushitani, H.; Ohtsuki, C.; Sakka, S.; Yamamuro, T. Chemical reaction of bioactive glass and glass-ceramics with a simulated body fluid. J. Mater. Sci. Mater. Med., 1992, 3, 79-83.

[154] Poologasundarampillai, G.; Yu, B.; Tsigkou, O.; Valliant, E.; Yue, S.; Lee, P.D.; Hamilton, R.W.; Stevens, M.M.; Kasuga, T.; Jones, J.R. Bioactive silicapoly(y-glutamic acid) hybrids for bone regeneration: effect of covalent coupling on dissolution and mechanical properties and fabrication of porous 
scaffolds. Soft Matter, 2012, 8, 4822-4832.

[155] McQuillan, D.J.; Richardson, M.D.; Bateman, J.F. Matrix deposition by a calcifying human osteogenic sarcoma cell line (SAOS-2). Bone, 1995, 16, 415426.

[156] Maeda, H.; Kasuga, T.; Hench, L.L. Preparation of poly(I-lactic acid)- polysiloxane-calcium carbonate hybrid membranes for guided bone regeneration. Biomaterials, 2006, 27, 1216-1222.

[157] Ren, L.; Tsuru, K.; Hayakawa, S.; Osaka, A. Synthesis and characterization of gelatin-siloxane hybrids derived through sol-gel procedure. J. Sol-Gel Sci. Technol., 2001, 21, 115-121.

[158] Ren, L.; Tsuru, K.; Hayakawa, S.; Osaka, A. Novel approach to fabricate porous gelatin-siloxane hybrids for bone tissue engineering. Biomaterials, $2002,23,4765-4773$

[159] Douglas, T.E.L.; Krawczyk, G.; Pamula, E.; Declercq, H.A.; Schaubroeck, D.; Bucko, M.M.; Balcaen, L.; Van Der Voort, P.; Bliznuk, V.; van den Vreken, N.M.; Dash, M.; Detsch, R.; Boccaccini, A.R.; Vanhaecke, F.; Cornelissen, M.; Dubruel, P. Generation of composites for bone tissue- engineering applications consisting of gellan gum hydrogels mineralized with calcium and magnesium phosphate phases by enzymatic means. J. Tissue Eng. Regen. Med., 2014, doi: 10.1002/term.1875.

[160] Brown, E.M.; MacLeod, R.J. Extracellular calcium sensing and extracellular calcium signaling. Physiol. Rev., 2001, 81, $239-297$.

[161] Ma, Z.; Kotaki, M.: Inai, R.: Ramakrishna, S. Potential of nanofiber matrix as tissue-engineering scaffolds. Tissue Eng., 2005, 11, 101-109.

[162] Li, W.J.; Laurencin, C.T.; Caterson, E.J.; Tuan, R.S.; Ko, F.K. Electrospun nanofibrous structure: a novel scaffold for tissue engineering. J. Biomed. Mater. Res., 2002, 60, 613-621.

[163] Hutmacher, D.W.; Dalton, P.D. Melt electrospinning. Chem. Asian J., 2011, 6, 44-56.

[164] Taylor, G. Electrically driven jets. Proc. R. Soc. Lond. A. Math. Phys. Sci., $1969,313,453-475$.

[165] Reneker, D.H.; Yarin, A.L.; Fong, H.; Koombhongse, S. Bending instability of electrically charged liquid jets of polymer solutions in electrospinning. J. Appl. Phys., 2000, 87, 4531-4547.

[166] Hohman, M.M.; Shin, M.; Rutledge, G.; Brenner, M.P. Electrospinning and electrically forced jets. I. Stability theory. Phys. Fluids, 2001, 13, $2201-2220$.

[167] Reneker, D.H.; Yarin, A.L. Electrospinning jets and polymer nanofibers. Polymer (Guildf), 2008, 49, 2387-2425.

[168] Lu, H.; Zhang, T.; Wang, X.P.; Fang, Q.F. Electrospun submicron bioactive glass fibers for bone tissue scaffold. J. Mater. Sci. Mater. Med., 2009, 20, 793-798.

[169] Li, W.-J.; Mauck, R.L.; Cooper, J.A.; Yuan, X.; Tuan, R.S. Engineering controllable anisotropy in electrospun biodegradable nanofibrous scaffolds for musculoskeletal tissue engineering. J. Biomech., 2007, 40, 1686-1693.

[170] Charles-Harris, M.; Koch, M.A.; Navarro, M.; Lacroix, D.; Engel, E.; Planell, J.A. A PLA/calcium phosphate degradable composite material for bone tissue engineering: an in vitro study. J. Mater. Sci. Mater. Med., 2008, 19, 1503-1513.

[171] Prabhakaran, M.P.; Venugopal, J.; Ramakrishna, S. Electrospun nanostructured scaffolds for bone tissue engineering. Acta Biomater., 2009, 5, 28842893.

[172] Choi, S.; Lee, S.G.; Im, S.S.; Kim, S.H.; Joo, Y.L. Silica nanofibers from electrospinning/sol-gel process. J. Mater. Sci. Lett., 2003, 22, 891-893.

[173] Rajzer, I.; Menaszek, E.; Kwiatkowski, R.; Chrzanowski, W. Bioactive nanocomposite PLDL/nano-hydroxyapatite electrospun membranes for bone tissue engineering. J. Mater. Sci. Mater. Med., 2014, 25, 1239-1247.

[174] Huang, Z.M.; Zhang, Y.Z.; Kotaki, M.; Ramakrishna, S. A review on polymer nanofibers by electrospinning and their applications in nanocomposites. Compos. Sci. Technol., 2003, 63, 2223-2253.

[175] Song, J.H.; Yoon, B.H.; Kim, H.E.; Kim, H.W. Bioactive and degradable hybridized nanofibers of gelatin-siloxane for bone regeneration. J. Biomed. Mater. Res., A, 2008, 84, 875-884.

[176] Yeong, W.Y.; Chua, C.K.; Leong, K.F.; Chandrasekaran, M. Rapid prototyping in tissue engineering: challenges and potential. Trends Biotechnol., 2004, 22, 643-652.

[177] Kim, G.; Son, J.; Park, S.; Kim, W. Hybrid process for fabricating 3D hierarchical scaffolds combining rapid prototyping and electrospinning. Macromol. Rapid Commun., 2008, 29, 1577-1581.

[178] Meseguer-Olmo, L.; Vicente-Ortega, V.; Alcaraz-Baños, M.; Calvo-Guirado, J.L.; Vallet-Regí, M.; Arcos, D.; Baeza, A. In vivo behavior of Sihydroxyapatite/polycaprolactone/DMB scaffolds fabricated by 3D printing. J. Biomed. Mater. Res., Part A, 2013, 101A, $2038-2048$.

[179] Wu, X.; Liu, Y.; Li, X.; Wen, P.; Zhang, Y.; Long, Y.; Wang, X.; Guo, Y.: Xing, F.; Gao, J. Preparation of aligned porous gelatin scaffolds by unidirectional freeze-drying method. Acta Biomater., $2010,6,1167-1177$.

[180] Darder, M.; Aranda, P.; Ruiz-Hitzky, E. Bionanocomposites: A new concept of ecological, bioinspired, and functional hybrid materials. Adv. Mater., 2007, 19, 1309-1319.

[181] Reverchon, E.; Pisanti, P.; Cardea, S. Nanostructured PLLA-hydroxyapatite scaffolds produced by a supercritical assisted technique. Ind. Eng. Chem. Res., 2009, 48, 5310-5316.

[182] Delabarde, C.; Plummer, C.G.; Bourban, P.E.; Månson, J.A. Biodegradable polylactide/hydroxyapatite nanocomposite foam scaffolds for bone tissue engineering applications. J. Mater. Sci. Mater. Med., 2012, 23, 1371-1385.

[183] Montjovent, M.; Mathieu, L.; Schmoekel, H.; Mark, S.; Bourban, P.; Zambelli, P.; Laurent-Applegate L.A.; Pioletti, D.P. Repair of critical size defects in the rat cranium using ceramic-reinforced PLA scaffolds obtained by supercritical gas foaming. J. Biomed. Mater. Res., Part A, $2007,83,41-51$.

[184] Tocco, I.: Zavan, B.; Bassetto, F.; Vindigni, V. Nanotechnology-based therapies for skin wound regeneration. J. Nanomater., $2012,714134$.

[185] Seal, B. Polymeric biomaterials for tissue and organ regeneration. Mater. Sci. Eng. R Reports, 2001, 34, 147-230.

[186] Sun, J.; Tan, H. Alginate-based biomaterials for regenerative medicine applications. Materials (Basel), 2013, 6, 1285-1309.

[187] Ziv-Polat, O.; Topaz, M.; Brosh, T.; Margel, S. Enhancement of incisional wound healing by thrombin conjugated iron oxide nanoparticles. Biomaterials, 2010, 31, 741-747.

[188] Friedman, A.J.; Han, G.; Navati, M.S.; Chacko, M.; Gunther, L.; Alfieri, A.; Friedman, J.M. Sustained release nitric oxide releasing nanoparticles: Characterization of a novel delivery platform based on nitrite containing hydrogel/glass composites. Nitric Oxide, 2008, $19,12-20$.

[189] Kawai, K.; Larson, B.J.; Ishise, H.; Carre, A.L.; Nishimoto, S.; Longaker, M.; Lorenz, H.P. Calcium-based nanoparticles accelerate skin wound healing. PLoS One, 2011, 6, e27106.

[190] Chiang, H.; Jiang, C.C. Repair of articular cartilage defects: review and perspectives. J. Formos. Med. Assoc., 2009, 108, 87-101.

[191] Iwamoto, M.; Ohta, Y.; Larmour, C.: Enomoto-Iwamoto, M. Toward regeneration of articular cartilage. Birth Defects Res. Part C Embryo Today Rev., 2013, 99, 192-202.

[192] Lee, K.Y.; Mooney, D.J. Alginate: Properties and biomedical applications. Prog. Polym. Sci, 2012, 37, 106-126.

[193] Chang, S.C.N.; Rowley, J.A.; Tobias, G.; Genes, N.G.; Roy, A.K.; Mooney, D.J.; Vacanti, C.A.; Bonassar, L.J. Injection molding of chondrocyte/alginate constructs in the shape of facial implants. J. Biomed. Mater. Res., 2001, 55, 503-511.

[194] Chang, S.C.N.; Tobias, G.; Roy, A.K.; Vacanti, C.A.; Bonassar, L.J. Tissue engineering of autologous cartilage for craniofacial reconstruction by injection molding. Plast. Reconstr. Surg., 2003, 112, 793-799; discussion 800-801. 
[195] Hoemann, C.D.; Hurtig, M.; Rossomacha, E.; Sun, J.; Chevrier, A.; Shive, M.S.; Buschmann, M.D. chitosan-glycerol phosphate/blood implants improve hyaline cartilage repair in ovine microfracture defects. J. Bone Jt. Surg., 2005, 87, 2671-2686.

[196] Huang, X.; Yang, D.; Yan, W.; Shi, Z.; Feng, J.; Gao, Y.; Weng, W.; Yan, S. Osteochondral repair using the combination of fibroblast growth factor and amorphous calcium phosphate/poly(l-lactic acid) hybrid materials. Biomaterials, 2007, 28, 3091-3100.

[197] Gu, X.; Ding, F.; Williams, D.F. Neural tissue engineering options for peripheral nerve regeneration. Biomaterials, 2014, 35, 6143-6156.

[198] Fabbro, A.; Prato, M.; Ballerini, L. Carbon nanotubes in neuroregeneration and repair. Adv. Drug Deliv. Rev., 2013, 65, $2034-2044$.

[199] Jin, G.Z.; Kim, M.; Shin, U.S.; Kim, H.W. Neurite outgrowth of dorsal root ganglia neurons is enhanced on aligned nanofibrous biopolymer scaffold with carbon nanotube coating. Neurosci. Lett., 2011, 501, 10-14

[200] Tavangarian, F.; Li, Y. Carbon nanostructures as nerve scaffolds for repairing large gaps in severed nerves. Ceram. Int., 2012, 38, 6075-6090.

[201] Cho, Y.: Borgens, R. Ben. The effect of an electrically conductive carbon nanotube/collagen composite on neurite outgrowth of PC12 cells. J. Biomed. Mater. Res., Part A, 2010, 95A, 510-517.

[202] Ostrovidov, S.; Shi, X.; Zhang, L.; Liang, X.; Kim, S.B.; Fujie, T.; Ramalingam, M.; Chen, M.; Nakajima, K.; Al-Hazmi, F.; Bae, H.; Memic, A.; Khademhosseini, A. Myotube formation on gelatin nanofibers - Multi- walled carbon nanotubes hybrid scaffolds. Biomaterials, 2014, 35, 62686277.

[203] Obarzanek-Fojt, M.; Elbs-Glatz, Y.; Lizundia, E.; Diener, L.; Sarasua, J.R.; Bruinink, A. From implantation to degradation - are poly (Ilactide)/multiwall carbon nanotube composite materials really cytocompatible? Nanomedicine, 2014, 10, 1041-1051. 